\title{
URANS Simulations for a Flooded Ship in Calm Water and Regular Beam Waves
}

\author{
Hamid Sadat-Hosseini ${ }^{1}$, Dong-Hwan Kim¹, Pablo M. Carrica1, Shin Hyung Rhee ${ }^{2}$, Frederick \\ Stern $^{1 *}$
}

${ }^{1}$ IIHR - Hydroscience \& Engineering, The University of Iowa, Iowa City, IA, 52242, USA

${ }^{2}$ Department of Naval Architecture \& Ocean Engineering, Seoul National University, Seoul, South Korea

*Corresponding author: Email: frederick-stern@uiowa.edu; Tel: 319-335-5215; Fax: 319-335-5238

\begin{abstract}
CFD simulations are conducted for zero-speed damaged passenger ship SSRC in calm water and waves with 6DOF motions including flooding procedure in calm water, roll decay in calm water and motions in regular beam waves for various wavelengths. The simulations model the $6 \mathrm{DOF}$ soft spring experimental mount, the one- and two-room flooding compartment configurations, including both intact and damaged conditions. For flooding and roll decay, simulations show ability to predict the trend of increases in roll period and damping due to flooding, as reported in ITTC. The damping magnitudes were often under-predicted with large errors while the roll period and compartment water height were well predicted. Two-room compartment simulation showed three times larger damping than one-room compartment cases whereas the roll period was similar for both conditions. For wave cases, all motions show primarily 1st order responses, except for parametric roll condition which shows large $1 / 2$ harmonic responses for the intact ship. The 2 nd order responses are small for both damaged and intact ship. The larger roll period and damping for the damaged ship shift the peak of responses to smaller wave frequency and reduce the amplitude of responses. The average error is often large for 1st order intact ship pitch and damaged ship surge and pitch. The errors are larger for
\end{abstract}


most $1 / 2$ and 2 nd order responses. Large errors could be partially due to the complex mounting system

in the experiment. Overall, current CFD results show better predictions than those reported for

potential flow solvers even though the computational cost is larger.

Keywords: CFD, Damage Ship Stability, Calm Water, Beam Waves

\section{NOMENCLATURE}

\begin{tabular}{|c|c|}
\hline A & wave amplitude \\
\hline B & 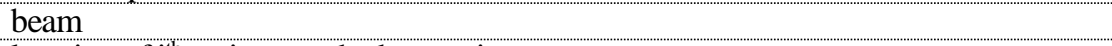 \\
\hline $\mathrm{C}_{\mathrm{i}}(\mathrm{i}=1$ to 4$)$ & location of $\mathrm{i}^{\text {th }}$ spring attached to carriage \\
\hline CPUh & CPU time to run simulation (in hour) \\
\hline $\mathrm{d}_{\mathrm{pi}}(\mathrm{i}=1$ to 4$)$ & distance from ship's center of gravity to $P_{i}$ in ship coordinate system \\
\hline $\mathrm{E} \% \mathrm{D}(=100 \times(\mathrm{D}-\mathrm{S}) / \mathrm{D})$ & Comparison error ( $D$ and $S$ are the experimental and simulation values, respectively) \\
\hline F & total spring force in earth coordinate system \\
\hline $\mathrm{F}^{\prime}$ & total spring force in ship coordinate system \\
\hline$f_{d}$ & averaged damped roll frequency over k roll cycles \\
\hline $\mathrm{f}_{\mathrm{dk}}$ & damped roll frequency for $\mathrm{k}^{\text {th }}$ roll cycle \\
\hline $\mathrm{F}_{\mathrm{i}}(\mathrm{i}=1$ to 4$)$ & $\mathrm{i}^{\text {th }}$ spring force vector in earth coordinate system \\
\hline $\mathrm{F}_{\mathrm{i}}^{\prime}(\mathrm{i}=1$ to 4$)$ & $\mathrm{i}^{\text {th }}$ spring force vector in ship coordinate system \\
\hline $\operatorname{Fr}(=U / \sqrt{ }(\mathrm{Lg}))$ & Froude Number \\
\hline$f_{w}$ & wave frequency \\
\hline $\mathrm{f}_{\mathrm{z} \theta}$ & Heave and pitch natural frequency \\
\hline $\mathrm{f}_{\mathrm{i}}(\mathrm{i}=\mathrm{A}, \mathrm{B}, \mathrm{C}, \mathrm{D}, \mathrm{E})$ & water height frequency at wave probes A-E \\
\hline $\mathrm{f}_{\phi} \quad-n$ & natural roll frequency \\
\hline g & Gravitational acceleration \\
\hline $\mathrm{GM}$ & distance from vertical center of gravity to metacenter \\
\hline $\mathrm{H}(=2 \mathrm{~A})$ & wave height \\
\hline $\mathrm{K}$ & Spring stiffness \\
\hline $\mathrm{k}(=2 \pi \lambda)$ & wave number \\
\hline K,M,N & roll, pitch, and yaw moments \\
\hline KG & vertical position of center of gravity from keel \\
\hline $\mathrm{k}_{\mathrm{xx}}$ & radius of gyration along $\mathrm{x}$-axis \\
\hline $\mathrm{k}_{\mathrm{yy}}$ & radius of gyration along $y$-axis \\
\hline $\mathrm{k}_{\mathrm{zz}}$ & radius of gyration along z-axis \\
\hline $\mathrm{L}$ & ship length \\
\hline LCG & longitudinal position of center of gravity \\
\hline$M^{\prime}$ & total spring moment in ship coordinate system \\
\hline $\mathrm{M}_{\mathrm{i}}^{\prime}(\mathrm{i}=1$ to 4$)$ & $\mathrm{i}^{\text {th }}$ spring moment vector in ship coordinate system \\
\hline $\mathrm{P}_{\mathrm{i}}(\mathrm{i}=1$ to 4$)$ & location of $i^{\text {th }}$ spring attached to ship \\
\hline $\mathrm{R}$ & rotational matrix from ship to earth coordinate system \\
\hline $\mathrm{r}_{\mathrm{Ci}}(\mathrm{i}=1$ to 4$)$ & displacement vector of $C_{i}$ in earth coordinate system \\
\hline $\mathrm{r}_{\mathrm{G}}(=[\mathrm{x}, \mathrm{y}, \mathrm{z}, \phi, \theta, \psi])$ & displacement vector of ship's center of gravity respect to earth coordinate system \\
\hline $\mathrm{r}_{\mathrm{Pi}}(\mathrm{i}=1$ to 4$)$ & displacement vector of $P_{i}$ in earth coordinate system \\
\hline $\mathrm{T}$ & draft -1 \\
\hline $\mathrm{t}$ & time \\
\hline $\mathrm{T}_{\mathrm{w}}\left(=1 / \mathrm{f}_{\mathrm{w}}\right)$ & wave period \\
\hline U & 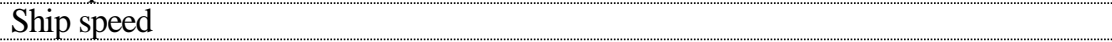 \\
\hline $\mathrm{U}_{\mathrm{I}}, \mathrm{U}_{\mathrm{G}}, \mathrm{U}_{\mathrm{T}}, \mathrm{U}_{\mathrm{SN}}$ & Iterative, grid, time step and simulation uncertainties \\
\hline $\mathrm{x}, \mathrm{y}, \mathrm{z}$ & surge, sway, and heave motions \\
\hline $\mathrm{X}, \mathrm{Y}, \mathrm{Z}$ & surge, sway, and heave forces \\
\hline $\mathrm{x}_{\mathrm{n}}, \mathrm{y}_{\mathrm{n}}, \mathrm{z}_{\mathrm{n}}(\mathrm{n}=1 / 2,1,2)$ & $n^{\text {th }}$ harmonic amplitude of surge, sway, and heave motions \\
\hline $\mathrm{X}_{\mathrm{nn}}, \mathrm{Y}_{\mathrm{n},}, \mathrm{Z}_{\mathrm{n}}(\mathrm{n}=1 / 2,1,2)$ & $\mathrm{n}^{\text {th }}$ harmonic phase of surge, sway, and heave motions \\
\hline$y+$ & non-dimensional distance from wall \\
\hline$\alpha$ & averaged linear roll damping coefficient over k roll cycles \\
\hline$\alpha_{k}\left(=\delta_{k} f_{d k}\right)$ & linear roll damping coefficient based on logarithmic roll decrement method \\
\hline$\delta$ & averaged logarithmic roll decrement over k roll cycles \\
\hline
\end{tabular}




\begin{tabular}{|c|c|}
\hline$\delta_{\mathrm{k}}$ & logarithmic roll decrement using successive maxima or minima for $\mathrm{k}^{\text {th }}$ roll decay cycle \\
\hline$\zeta_{\mathrm{i}}(\mathrm{i}=\mathrm{A}, \mathrm{B}, \mathrm{C}, \mathrm{D}, \mathrm{E})$ & water height at wave probes A-E \\
\hline $\bar{\zeta}_{\mathrm{i}}(\mathrm{i}=\mathrm{A}, \mathrm{B}, \mathrm{C}, \mathrm{D}, \mathrm{E})$ & mean water height at wave probes A-E \\
\hline$\zeta_{\text {in }}(\mathrm{i}=\mathrm{A}, \mathrm{B}, \mathrm{C}, \mathrm{D}, \mathrm{E})$ & $n^{\text {th }}$ harmonic amplitude of water height at wave probes A-E \\
\hline$\lambda$ & wave length \\
\hline$\phi, \theta, \psi$ & roll, pitch, and yaw motions \\
\hline $\bar{\phi}$ & heel angle (or time-averaged roll angle) \\
\hline$\phi_{\mathrm{i}}$ & initial roll angle \\
\hline$\phi_{\mathrm{m}}$ & averaged mean roll angle over k roll cycles \\
\hline$\phi_{\mathrm{mk}}$ & mean roll angle for $\mathrm{k}^{\text {th }}$ roll cycle \\
\hline$\phi_{n}, \theta_{n}, \psi_{n}(n=1 / 2,1,2)$ & $n^{\text {th }}$ harmonic amplitude of roll, pitch, and yaw motions \\
\hline$\phi_{\mathrm{en}}, \theta_{\mathrm{sn}}, \psi_{\mathrm{en}}(\mathrm{n}=1 / 2,1,2)$ & $\mathrm{n}^{\text {th }}$ harmonic phase of roll, pitch, and yaw motions \\
\hline$\omega_{\mathrm{w}}\left(=2 \pi \mathrm{f}_{\mathrm{w}}\right)$ & wave angular frequency \\
\hline
\end{tabular}

\section{INTRODUCTION}

Dynamic stability is of high priority in ship safety but poorly understood for a damaged ship. One of the main safety considerations for a damaged ship is its behavior in the transition from the initial upright position to its final equilibrium position. Accurate prediction of the floodwater dynamics and flooding process in multipart geometries along with ship motions is crucial in assessment of a damaged ship behavior and its safety.

Damaged ship behavior has been a research focus as summarized last several ITTC Stability in Waves Committee Reports. Passenger and ferry ships are specified as benchmarks for experimental and simulation studies in calm water and regular and irregular waves. For the zero-speed calm water damaged condition, the roll period and damping are larger than for the damaged condition. Increasing KG showed larger roll period and smaller damping and increasing floodwater height showed both larger roll period and damping. Tests for regular and irregular waves indicated second harmonic roll motion and capsize, respectively (ITTC, 2002). Recent focus is on time to flood and safe return to port and survival boundaries in irregular waves.

Potential flow methods are the common numerical approach to study the damaged ship stability (Papanikolaou et al., 2000; Palazzi and De Kat, 2004). The 6DOF damaged ship motions in waves are solved by various strip theory or panel-based methods. The viscous effects are treated by semiempirical approaches. The inflow and outflow of water through the openings is computed by the 
Bernoulli-based equations including orifice, sluice gate and weir equations. The non-linear sloshing effect inside the compartment is often neglected, and the internal water surface is assumed to be either horizontal or a freely movable plane. The capability of potential flow methods for a damaged passenger ship (PRR1) with zero-speed was evaluated in 23rd ITTC using several benchmark experimental data for free roll decay in calm water, motion in regular waves and survivability boundaries in irregular waves (ITTC, 2002). The potential flow predictions were only assessed for motions and not evaluated for floodwater height. The results from several potential flow tools showed overestimation of the damped roll frequency $(\mathrm{E}=-22 \% \mathrm{D})$ and underestimation of logarithmic roll damping coefficient $(\mathrm{E}=62 \% \mathrm{D})$ for roll decay, scattered results for regular waves with large over prediction for roll frequency $(\mathrm{E}=-15 \% \mathrm{D})$ and amplitude $(\mathrm{E}=-91 \% \mathrm{D})$, and only qualitative agreement with experimental data in irregular waves. Note that the comparison errors were not given in ITTC report and calculated by authors as $\mathrm{E}=(\mathrm{D}-\mathrm{S}) \% \mathrm{D}$ between the experimental data (D) and simulation (S) values.

The CFD study of a damaged ship is performed for very limited cases. Few studies only used CFD to predict the dynamic effect of floodwater and then coupled with the potential flow solvers for ship motion prediction (Strasser et al., 2009; Gao et al., 2013). Therefore, the accuracy of the predicted motions was still associated with the level of nonlinearity implemented in the potential flow solver. The complete physics-based CFD simulations are conducted only for a ship in calm water with a semi-captive condition. Gao and Vassalos (2011) demonstrated the capability of CFD prediction for the roll decay prediction of a damaged ship for initial angle $\pm 5^{\circ}$. The simulations were conducted for $1 \mathrm{DOF}$ and 2DOF conditions with roll and roll-sway motion. Gao et al. (2011) validated motions and floodwater heights for a 3DOF damaged barge in calm water, free to heave, roll and pitch. The time history of roll motion showed a quite large error $(\mathrm{E} \sim 200 \% \mathrm{D})$ during the initial part of the flooding procedure while it is predicted well after the compartment is fully flooded. Additionally, the heave and pitch motions were well predicted with $\mathrm{E}<5 \% \mathrm{D}$. The trends of computed floodwater heights were 
generally consistent with the experimental measurements. However, there were differences between simulation and experiment which could not be quantified.

Herein, the capabilities of physics-based CFD simulations are assessed for zero-speed ship flooding and roll decay in calm water and regular beam waves with 6DOF motions using the experimental data provided by Lee et al. (2015). The simulations model the soft spring experimental mount, the one- and two-room flooding compartment configurations, including both intact and damaged conditions. The errors are evaluated for floodwater and motions using the experimental data. The level of the errors is compared with that from previous potential flow studies and the cost and benefit for the current approach is described.

\section{EXPERIMENTAL VALIDATION DATA}

\subsection{Facility, model, mount, measurement systems}

The tests are conducted in the Seoul National University (SNU) towing tank, which is $110 \mathrm{~m}$ long, $8 \mathrm{~m}$ wide and $3.5 \mathrm{~m}$ deep. A 1:82.75 scale, $\mathrm{L}=3.0 \mathrm{~m}$ geosim of the SSRC passenger ship is used for the experiments. Model-scale geometric parameters are summarized in Table 1. The model is appended with a compartment installed at the mid-ship as shown in Fig. 1a. The compartment is divided by a side wall into two rooms connected through a small hole so that there is a cross-flooding between the rooms. Both compartment rooms have ventilation holes on their roof to have atmosphere pressure inside the rooms during flooding. The flooding occurs through a gate located on the starboard side of the compartment. The compartment layout is shown in Fig. $1 b$.

In the experiments, the ship was located in the mid-tank, free to all degree of motions. For wave cases, the aft and fore of the model were attached to the stationary carriage using four springs to compensate the drift motion of the ship in the experiment. All springs were initially installed to be parallel and close to the free surface. A simple mass-spring measurement showed that the spring force 
has linear behavior within the range of possible spring length during the experiment. The effective spring stiffness is shown to be $5.946 \mathrm{~N} / \mathrm{m}$ and the spring forces are off by $6.8148 \mathrm{~N}$ from the one estimated by $\mathrm{F}=\mathrm{Kx}$. For flooding of the compartment, its gate was opened using an air cylinder that pulled up the gate in the vertical direction. The opening time was approximately 0.09 second in model scale and it was confirmed that the induced roll motion due to the opening mechanism was negligible.

Two measurement systems were used for the experiments: flooding water and ship motion measurement systems. The height of the flooding water was measured by five capacitance type wave probes at locations A, B, C, D, E in the compartment $\left(\zeta_{\mathrm{i}} ; \mathrm{i}=\mathrm{A}, \mathrm{B}, \mathrm{C}, \mathrm{D}, \mathrm{E}\right)$ as shown in Fig. 1b. The 6DOF motion responses $(\mathrm{x}, \mathrm{y}, \mathrm{z}, \phi, \theta, \psi)$ were measured with a combination of the accelerometers and inertial measurement unit (IMU). The IMU was mainly used for the roll motion measurement in the free roll decay test. The accelerometers were used to obtain 6DOF motion responses from the test results in regular waves. From the measured accelerations, the 6DOF motion responses of the model were obtained using the strap-down method. It should be noted that the accelerations were first filtered using band-pass filtering in Matlab and then numerically integrated to get velocities. The velocity data were filtered again and numerically integrated to produce displacement. Thus, the experimental data reduction technique might have influences on the accuracy of the data. More details of the experimental setup and measurement system are reported in Lee et al. $(2012,2014)$ and Lim et al. (2015).

\subsection{Conditions and validation variables}

The experimental test matrices are provided in Table 2. The tests include flooding procedure in calm water for damaged SSRC, roll decay in calm water for intact and damaged SSRC, and motions in regular waves for intact and damaged SSRC. All tests were performed for zero Fr with free motions. Roll decay test were conducted by imposing different initial roll angle including $\phi_{\mathrm{i}}=-13.7^{\circ}$ and $-20.5^{\circ}$ for the intact ship and about $\phi_{\mathrm{i}}= \pm 16^{\circ}$ and $\pm 26^{\circ}\left(+15.9^{\circ}\right.$ and $-15.6^{\circ} ;+26.7^{\circ}$ and $\left.-25.5^{\circ}\right)$ for the damaged 
ship with one-room compartment and $\phi_{\mathrm{i}}=-28.6^{\circ}$ with two-room compartment. The negative initial roll angle represents rolling toward the damaged side. The regular waves tests were conducted for two wave steepness conditions $H / \lambda=1 / 100$ and $1 / 60$ as shown in Table 2 . The wave periods were 1 , $1.5,1.995,2.055,2.155$ seconds, chosen to be distributed around the natural roll period of the intact SSRC which is 2.055 seconds (see Table 1 ). The wave periods correspond to $\lambda / L=0.52,1.17,1.99$, 2.2, 2.42. The wave heading was $90 \mathrm{deg}$ (beam waves), approaching the ship from the damaged side. Both rooms were included in the damaged ship tests in waves.

As shown in Tables 2, the validation variables for calm water cases include $\phi$ and $\zeta_{\mathrm{A}, \mathrm{B}, \mathrm{C}}$ for flooding and $\phi$ for all roll decay cases plus $\zeta_{\mathrm{A}, \mathrm{B}, \mathrm{C}}$ and $\zeta_{\mathrm{A}, \mathrm{B}, \mathrm{C}, \mathrm{D}, \mathrm{E}}$ for $\phi_{\mathrm{i}}=-25.5^{\circ}$ and $-28.6^{\circ}$, respectively. For waves, the validation variables include $\mathrm{x}, \mathrm{y}, \mathrm{z}, \phi, \theta, \psi$ and $\zeta_{\mathrm{A}, \mathrm{B}, \mathrm{C}, \mathrm{D}, \mathrm{E} .}$

\section{COMPUTATIONAL METHODS}

The code CFDShip-Iowa v4.5 (Huang et al., 2008) is used for the CFD computations. The simulations are conducted in absolute inertial earth-fixed coordinates. $k-\varepsilon / k-\omega$ with no wall function is used for turbulence model. A single-phase level-set method is used for free-surface capturing. 6DOF rigid body equations of motion are solved to predict the ship motions. Dynamic overset grid technique is used to allow motions for the ship. The governing equations are discretized using finite difference schemes on body-fitted curvilinear grids. The time derivatives in the turbulence and momentum equations are discretized using second order finite Euler backward difference. Convection terms in the turbulence and momentum equations are discretized with higher order upwind formula. The viscous terms in momentum and turbulent equations are computed with similar considerations using a second order difference scheme. Projection method, a two-stage fractional step scheme, is employed to effectively couple pressure and velocity. In order to solve the system of discretized governing equations, between three and five inner iterations are used in each time step and 
solutions are considered to be converged once the errors for velocities, pressure, and level set reach to less than $10^{-5}, 10^{-8}$, and $10^{-5}$ respectively.

\subsection{Soft spring mount modeling}

Similar to the experimental setup, springs were included in the regular wave simulations to counteract the wave drift forces while the ship model is still free to all modes of motion. The spring forces for all $6 \mathrm{DOF}$ were computed in earth coordinate system and then transformed to the ship-fixed coordinate system with the origin at the center of gravity $(G)$. The spring moments in ship-fixed coordinate were calculated by the cross product of the moments' arm and forces described in the shipfixed coordinate. The details of spring forces and moments calculation are explained in Appendix A.

After calculating the spring forces and moments, they were added to the total forces and moments applied on the right-hand side of the equations of motion. The total forces and moments are the fluid forces and moments integrated at each time step not only on the ship hull but also inside the flooded compartment. This means that the change of the ship mass and/or center of gravity due to the flooding are already included in the integrated forces and moments. Therefore, there's no need to modify the ship mass, moment of inertia, or center of gravity unlike the traditional methods. In the traditional methods, the flooded compartments are treated often as an additional weight to the ship. The added weight then changes the center of gravity and moments of inertia of the ship and consequently the equations of motion have to be solved for the ship with the new properties.

\subsection{Domain, boundary conditions, and grids}

The computational domain extends from $-1.5<\mathrm{x}<1.5,-1.2<\mathrm{y}<1.2,-1<\mathrm{z}<0.25$ for roll decay and flooding procedure simulation and $-1.5<\mathrm{x}<1.5,-2<\mathrm{y}<1,-1<\mathrm{z}<0.25$ for regular wave simulations, in dimensionless coordinates based on the ship length. The longitudinal ship axis is aligned with the x- 
axis with the bow at $\mathrm{x}=0$ and the stern at $\mathrm{x}=1$. The $\mathrm{y}$-axis is positive to starboard and the $\mathrm{z}$-axis is positive upward. The free surface at rest lies at $\mathrm{z}=0$.

Several types of boundary conditions are used in this CFD study. The far field boundary conditions are imposed on the top and bottom of the background. The no-slip condition is applied on the solid surfaces on the hull or inside the compartment. On the sides, the zero gradient boundary condition is applied. For calm water simulation, the inlet and exit boundary conditions are used for inlet and outlet of the domain. For waves, the inlet and outlet boundary conditions are calculated from the linear potential flow solution of waves.

The computational grids are overset, with independent grids assembled together to generate the total grid. The grid includes the ship hull boundary layer, compartment room 1 and 2, connection grids, ventilation pipe, refinements, and background. The boundary layer grids are small enough $(y+<1)$ to capture the boundary layer. Because the ship hull is symmetric respect to center-plane, the grid for one side of the ship was generated and then mirrored respect to center-plane. Two Cartesian grids are used for the inside of the rooms 1 and 2 of the compartment. Two connection grids are also used; one at the opening door located between the two rooms and another one located at the compartment door. A circular cylinder grid was designed for the ventilation pipe. Cartesian grids are used for several refinements around the ship. In addition, a Cartesian grid for the background is used to impose the far-field boundary conditions. The grid size ranges from $2.4 \mathrm{M}$ to $28.5 \mathrm{M}$ depending on the damage/intact and calm water/wave conditions of the simulations. For calm water cases, the grid size is $6.3 \mathrm{M}$ for the intact ship and $19.8 \mathrm{M}$ and $28.5 \mathrm{M}$ for the damaged ship with one- and two-room compartment, respectively. For wave cases, the grid size for the intact ship is $7.09 \mathrm{M}-12.2 \mathrm{M}$, finer for short wave cases. The grid size for the damaged ship is within $24.1 \mathrm{M}-27.1 \mathrm{M}$ grid points. For verification study, a fine grid with $19.9 \mathrm{M}$ and a coarse grid with $2.4 \mathrm{M}$ points are generated from the 
medium grid with $7.09 \mathrm{M}$ points using refinement/coarsen ratio of $\sqrt{2}$. The details of the grid system for damaged SSRC with the two-room compartment are shown in Fig. 2.

For the coarse grid (2.4M), 32 CPUs have been employed in parallel running for 72 hours wall clock time with the computational cost of $2300 \mathrm{CPUh}$. The computational cost increases with the increase of the grid size reaching to 97000 CPUh for the finest grid $(28.5 \mathrm{M})$ as it requires 288 CPUs running for about 14 days. Compared to the presumably negligible computational cost for potential flow solvers, the computational cost for current CFD study is large but it is a complete physics-based method which can be used for much more complex conditions compared to potential flow.

\subsection{Simulation conditions and analysis method}

The simulations are carried out in calm water and in waves, as shown in Table 2. The simulations are performed for the ship at zero Fr and free to all motions. For calm water, the flooding and intact/damaged roll decay cases with all different initial roll angles are simulated. For beam waves, the intact/damaged ship simulations are conducted only for the largest wave slope $(H / \lambda=1 / 60)$ for $\lambda / \mathrm{L}=0.52,1.17,1.99,2.2,2.42$. For all CFD simulations, $\mathrm{k}_{\mathrm{xx}}$ value is adjusted to $0.0501 \mathrm{~L}$ (see Table 1), found from preliminary roll decay simulation compared with the experimental data. It should be noted that the experimental setup usually has difficulties to fix $\mathrm{k}_{\mathrm{xx}}$ of the model to the desired value.

The validation variables are motions and water height as listed in Table 2. For flooding and roll decay, validation study is also conducted for the roll decay variables including mean roll angle $\left(\phi_{\mathrm{mk}}\right)$, time-averaged roll/heel angle $(\bar{\phi})$, roll damping frequency $\left(f_{\mathrm{dk}}\right)$, logarithmic decrement $\left(\delta_{\mathrm{k}}\right)$ and linear damping coefficient $\left(\alpha_{k}\right)$, and their averages over $k$ roll cycles $\left(\phi_{m}, f_{d}, \delta, \alpha\right)$, following roll decay analysis method described in Irvine et al. (2013). Harmonic analysis studies are conducted for the cases in beam waves for 6DOF motion responses and flooding water height per below: 


$$
\begin{gathered}
P(t)=\frac{P_{0}}{2}+\sum_{n=1}^{N} P_{n} \cos \left(n \omega_{w} t+P_{\varepsilon n}\right) \quad(\mathrm{n}=0,1,2, \ldots) \\
a_{n}=\frac{2}{T} \int_{0}^{T} P(t) \cos \left(n \omega_{w} t\right) d t \\
b_{n}=\frac{2}{T} \int_{0}^{T} P(t) \sin \left(n \omega_{w} t\right) d t \\
P_{n}=\sqrt{a_{n}^{2}+b_{n}^{2}} \\
\varepsilon_{n}=\tan ^{-1}\left(-\frac{b_{n}}{a_{n}}\right)
\end{gathered}
$$

where $P(\mathrm{t})$ is the time history of ship responses or floodwater height, $P_{0} / 2$ is the mean value, $P_{n}$ is the n-th harmonic amplitude and $P_{\varepsilon n}$ is the corresponding phase.

\section{VERIFICATION STUDY}

Iterative $U_{I}$, grid size $U_{G}$, and time step $U_{T}$ uncertainties were evaluated following Stern et al. (2001) and Xing and Stern (2010) for the intact configuration regular beam waves $\lambda=2.4 \mathrm{~L}$ and $\mathrm{H} / \lambda=1 / 60$ conditions. $\mathrm{U}_{\mathrm{I}}$ indicates the convergence error of CFD simulations due to the iteration of discrete equations. $\mathrm{U}_{\mathrm{G}}$ and $\mathrm{U}_{\mathrm{T}}$ indicate the discretization errors due to the grid size and time step. As the grid size and time step are refined, the solution of the discrete equations should approach the continuum solution. The verification variables included the $1^{\text {st }}$ harmonic amplitude of 6DOF motions $\left(\mathrm{x}_{1}, \mathrm{y}_{1}, \mathrm{Z}_{1}, \phi_{1}, \theta_{1}, \psi_{1}\right)$ and corresponding phases $\left(\mathrm{x}_{\varepsilon 1}, \mathrm{y}_{\varepsilon 1}, \mathrm{Z}_{\varepsilon 1}, \phi_{\varepsilon 1}, \theta_{\varepsilon 1}, \psi_{\varepsilon 1}\right)$.

The verification study showed $\mathrm{U}_{\mathrm{I}}<2 \% \mathrm{~S}_{1}$ for both $1^{\text {st }}$ harmonic amplitudes and phases with average values 0.75 and 1.22 , respectively. The largest $U_{I}$ was for the surge and heave motions i.e. $\mathrm{x}_{1}, \mathrm{Z}_{1}$ and $\mathrm{x}_{\varepsilon 1}, \mathrm{Z}_{\varepsilon 1}$. $\mathrm{U}_{\mathrm{G}} / \mathrm{U}_{\mathrm{T}}$ were mostly MC and $\mathrm{OC}$ with small/large $\mathrm{P}$ values thus far from asymptotic range with average values 1.28/0.18 and 9.64/3.49 for amplitudes and phases, respectively. Similar to $\mathrm{U}_{\mathrm{I}}$, the largest $\mathrm{U}_{\mathrm{G}} / \mathrm{U}_{\mathrm{T}}$ were for surge and heave motions. Overall, average simulation uncertainty $\mathrm{U}_{\mathrm{SN}}$ is 1.05 and 8.30 for amplitudes and phases, respectively. Further studies are needed for improved convergence and flooded conditions. 


\section{FLOODING}

Fig. 3 shows a comparison of the experimental and computational roll and flooded compartment wave elevations along with a snap shot of the predicted compartment flooding.

Fig. 4 shows comparisons of the experimental and computational $\phi_{\mathrm{mk}}$ Vs. initial roll angle $\left(\phi_{\mathrm{i}}\right)$ and $\mathrm{f}_{\mathrm{dk}}, \delta_{\mathrm{k}}$ and $\alpha_{\mathrm{k}} \mathrm{vs} . \phi_{\mathrm{mk}}$. Values are shown for both the port and starboard sides since the damaged roll response is asymmetric.

Tables 3 and 4 summarize the values and comparison error for the validation variables which are averaged over roll cycles. For $\mathrm{f}_{\mathrm{d}}, \mathrm{CFD}$ shows similar values for the intact and damaged side $(\sim 0.43$ $\mathrm{Hz}$ ) while EFD shows slightly larger value for the intact side. The error for $\mathrm{f}_{d}$ is $3.5 \% \mathrm{D}$ for the intact side and $1.37 \% \mathrm{D}$ for the damaged side, showing that CFD can predict the damaged ship roll frequency quite well unlike the potential flow tools (ITTC, 2002). CFD results also show good agreement for heel angle $\bar{\phi}$ with $\mathrm{E}<1 \% \mathrm{D}$, and compartment wave elevation frequency/mean $\mathrm{E}<9 \% / 3 \% \mathrm{D}$, but the linear damping are under predicted by $\mathrm{E}=43 \% \mathrm{D}$ and consequently mean roll angle are predicted three times larger than EFD. The damped roll frequency is about $10 \%$ less than the one available for the intact ship roll decay, due to the lower GM value. A snap shot of the flooding compartment in Fig. 3c shows water entry with sloshing. The sloshing frequency is close to the damped roll frequency as shown in Table 4.

\section{INTACT ROLL DECAY}

Fig. 5 shows the comparison of the experimental and computational intact condition roll decay $\phi_{\mathrm{mk}}$ vs. $\phi_{\mathrm{i}}$ and $\mathrm{f}_{\mathrm{dk}}, \delta_{\mathrm{k}}$ and $\alpha_{\mathrm{k}}$ vs. $\phi_{\mathrm{mk}} . \mathrm{f}_{\mathrm{dk}}$ changes slightly during roll decay confirming that the restoring moment of the ship is linear. The damped roll frequency is close to the roll natural frequency (see Table 1) and about $10 \%$ larger than the damped roll frequency in flooding, as explained earlier. Table 
3 summarizes the values and errors for the validation variables. For $\mathrm{f}_{\mathrm{d}}, \mathrm{E}$ is $<1 \% \mathrm{D}$ for both intact roll decay cases, showing a very good agreement with the experimental data. The E values for linear damping is about $37 \% \mathrm{D}$ for the intact case with smaller initial roll angle $\phi_{\mathrm{i}}$ while the error decreases to $16 \% \mathrm{D}$ for the case with larger $\phi_{\mathrm{i}}$. Nonetheless, the results show close agreement with the experimental data as the error for $\phi_{\mathrm{m}}$ is $4 \%$ for the case with smaller $\phi_{\mathrm{i}}$, dropping to $2.5 \%$ for the case with larger $\phi_{\mathrm{i}}$. The simulations display strong roll, sway and yaw coupling for which validation data is not available.

\section{DAMAGED ROLL DECAY}

Fig. 6 shows the comparison of the experimental and computational damaged condition roll decay and two compartment wave elevations along with a snap shot of the predicted two compartment flooding. The roll decay and floodwater height time histories show good agreement between the experimental data and CFD. Fig. 7 shows the comparison of the experimental and computational damaged condition roll decay $\phi_{\mathrm{mk}} \mathrm{vs} . \phi_{\mathrm{i}}$ and $\mathrm{f}_{\mathrm{dk}}, \delta_{\mathrm{k}}$ and $\alpha_{\mathrm{k}} \mathrm{vs} . \phi_{\mathrm{mk}}$. The experiments and simulations show scatter for the roll decay variables compared to the intact condition. The values are more scattered for portside. Tables 3 and 4 summarize the values and errors for the validation variables. Similarly as for flooding (and intact roll decay) the error for $\mathrm{f}_{\mathrm{d}}$ is quite small for all damaged roll decay cases. The error is $<2 \%$ for the cases with the one-room compartment and $<6 \%$ for the case with the two-room compartment, showing much better prediction for current CFD studies compared to the potential flow studies (E 22\%D), reported in ITTC (2002). $\alpha$ is mostly under predicted for current CFD simulations, same as for potential flow studies. However, the error values are within $2.4-29 \% \mathrm{D}$ which is less than those reported for potential flow studies (E 62\%D). The current results also show $\mathrm{E}=10.7-17 \% \mathrm{D}$ for $\phi_{\mathrm{m}}, \mathrm{E}=1.4-10 \% \mathrm{D}$ for the wave frequency and $\mathrm{E}=1.9-16 \% \mathrm{D}$ for the mean wave elevation. Overall, the simulations are in both qualitative and quantitative agreement with the experiments. The simulations display strong roll, sway and yaw coupling for which validation data is 
not available. The snap shot of the two compartment flooding in Fig. 6f shows water entry with sloshing. The sloshing frequency is close to the damped roll frequency as shown in Table 4.

Comparison of the intact and damaged roll decay shows the damped roll frequency is $10 \% / 11 \%$ smaller and damping is $15 \% / 45 \%$ larger for the damaged ship with one/two -room compartment, which follows the stated trends in ITTC Stability in Waves Committee report (2002). Since the water height is quite the same in both rooms, it was expected to have a similar effect on the damped roll frequency for both one- and two-room compartment cases. However, the flooding water acts as an anti-rolling tank and damps the roll motion more quickly for the case with the larger volume of flooded water. Additionally, the results showed average heel angle of -2.7 deg for one-room compartment and -5.84 deg for two-room compartment cases. The heel angle for one room compartment cases is comparable with the one for the flooding $(-2.5 \mathrm{deg})$.

\section{INTACT BEAM WAVES}

Fig. 8 shows the comparison of the experimental and computational intact beam waves 6DOF $1^{\text {st }}$ order (RAO), $1 / 2$ and $2^{\text {nd }}$ order responses. Table 5 summarizes the validation variable and $\mathrm{E}$ values. All motions show primarily $1^{\text {st }}$ order response, except for the case with largest wave frequency $\left(f_{w}=1\right.$ $\mathrm{Hz}$ ) which shows a large $1 / 2$ harmonic response. For that case, the wave frequency is about twice of the roll frequency and parametric rolling occurs. Parametric rolling is a large amplitude roll limitcycle oscillation which is not directly excited by the waves but it is a result of a dynamic instability of the roll motion. The dynamic instability occurs due to periodic changes of transverse stability (restoring moment) in waves and happens when the ratio of the natural roll frequency to the frequency of the restoring moment variation (or wave frequency) is about $1 / 2$ (Sadat-Hosseini et al., 2010). Fig. 8 shows the peak for roll, sway, and yaw responses are at same wave frequency indicating strong roll, sway, and yaw coupling. The $1^{\text {st }}$ order response for sway, roll and yaw are near the roll resonance condition while their large $1 / 2$ harmonic response is where the wave frequency is nearly twice of the 
roll frequency.

Table 5 shows the $\mathrm{E}$ values for $1^{\text {st }}$ order responses are often larger for pitch motion with the maximum error for $\lambda / \mathrm{L}=1.17$, as the EFD value is surprisingly too small for that wavelength condition. Overall, the averaged errors for $1^{\text {st }}$ order responses are quite similar for different wavelength conditions $(E \sim 31-35 \% \mathrm{D})$ without considering $\lambda / \mathrm{L}=1.17$ test case. For $1 / 2$ and $2^{\text {nd }}$ order responses, the average errors are $63-135 \% \mathrm{D}$ and $66-169 \% \mathrm{D}$, respectively, excluding the large errors often shown for $\lambda / L=0.52$ and 1.17 . Large $E$ values could be due to the complex mounting system in the experiment. Nonetheless, the simulations are in both qualitative and quantitative agreement with the experiments.

\section{DAMAGED BEAM WAVES}

Fig 9 shows the comparison of the experimental and computational damaged ship beam waves roll and flooded compartment wave elevations along with a snap shot of the predicted compartment flooding. Fig. 10 shows the comparison of the experimental and computational damaged beam waves $6 \mathrm{DOF} 1^{\text {st }}$ order $(\mathrm{RAO}), 1 / 2$ and $2^{\text {nd }}$ order responses. Tables 6 and 7 summarize the validation variable E values. All motions show primarily $1^{\text {st }}$ order response. Similarly as for the intact condition, the peaks for roll, sway and yaw responses are located at same wave frequency. Parametric roll (1/2 harmonic response) is not shown. The $2^{\text {nd }}$ order responses are small. The average $\mathrm{E}$ value for $1^{\text {st }}$ harmonic responses is within $27-77 \% \mathrm{D}$ for different wavelength conditions. Among all motions, the largest errors are often for surge and pitch motions. Even though the average error for $1^{\text {st }}$ harmonic roll amplitude for all the wavelength cases $(\mathrm{E}=42 \% \mathrm{D})$ is quite large, it is still much smaller than the value report for potential flow studies in ITTC report $(\mathrm{E} \sim 91 \% \mathrm{D})$ since the viscous effects are more accurately predicted. Similarly as for the intact condition, $1 / 2$ and $2^{\text {nd }}$ order variables show larger errors. Large error values could be due to the complex mounting system in the experiment. As shown in Table 7, the mean value of the compartment water height is well predicted with $\mathrm{E}<6.5 \% \mathrm{D}$ while $1 / 2$, 
$1^{\text {st }}$ and $2^{\text {nd }}$ harmonic amplitudes of the compartment water height show large errors. Nonetheless, the water heights are in both qualitative and quantitative agreement with the experiments, as shown in Fig. 9.

Comparing the intact and damaged ship shows that larger roll damping for the damaged ship reduces the amplitude of $1^{\text {st }}$ order responses. Additionally, the peak for $1^{\text {st }}$ order responses for the damaged ship (roll resonance) occurs at smaller wave frequency (longer wavelength) confirming larger roll period for the damaged ship. Similarly, the peak for $1 / 2$ order responses (parametric roll) should occur at longer wavelength due to flooding and thus more simulations between $\lambda / L=0.52$ and 1.17 are required to resolve the peak for $1 / 2$ order responses. Unlike the beam wave results for damaged passenger Ro-Ro ship reported in $23^{\text {rd }}$ ITTC report (2002), $2^{\text {nd }}$ order responses were small for SSRC damaged ship.

\section{CONCLUSION AND FUTURE RESEARCH}

URANS capabilities are assessed for zero-speed ship flooding using experimental validation data for flooding and roll decay in calm water and regular beam waves at zero speed.

For flooding and roll decay, the simulations show the ability to predict the trend of increases in roll period and damping due to flooding, as reported in ITTC. The damping magnitudes were often under-predicted similar to potential flow studies reported in ITTC. However, the errors are smaller for current $\mathrm{CFD}$ studies $(\mathrm{E}<43 \% \mathrm{D})$ compared to those reported for potential flow (E 62\%D) even thought the computational cost is larger. The damped roll frequency and floodwater heights were well predicted with $\mathrm{E}<5.5 \% \mathrm{D}$ and $\mathrm{E}<7 \% \mathrm{D}$, respectively. Therefore, $\mathrm{CFD}$ could predict the hydrodynamic added moment of inertia due to the flooding, unlike the potential flow as reported in ITTC. Two-room compartment simulation showed three times larger damping than one-room compartment cases whereas the roll period was similar for both conditions. The simulations display strong roll, sway and 
yaw coupling for which validation data is not available. The compartment showed sloshing with a frequency close to the damped roll frequency for all calm water cases.

For the beam wave cases, all motions show primarily $1^{\text {st }}$ order response, except for the parametric roll condition which shows a large $1 / 2$ harmonic response for the intact ship. The $2^{\text {nd }}$ order responses are small for both the damaged and intact ship, unlike ITTC report. The average error for $1^{\text {st }}$ order responses is $44 \% \mathrm{D}$ with large errors for the intact ship pitch motion and damaged ship surge and pitch motions. The results show that the average error for $1^{\text {st }}$ harmonic roll amplitude $(E=42 \% \mathrm{D})$ is much smaller than that for potential flow studies in ITTC report (E 91\%D) since the viscous effects are more accurately predicted. $1 / 2$ and $2^{\text {nd }}$ order variables show also large errors. Large error values could be due to the complex mounting system in the experiment. The compartment water height mean value was predicted very well $(\mathrm{E}<6.5 \% \mathrm{D})$ while $1 / 2,1^{\text {st }}$ and $2^{\text {nd }}$ order water height amplitude show large errors. The trend of responses against the wave frequency is similar for sway, roll, and yaw motions due to the strong coupling between them. For the damaged ship, the larger roll period and damping shift the peak of responses to smaller wave frequency and also reduce the amplitude of responses.

In future, the damaged ship behavior in beam waves approaching the ship from the intact side will be studied. Additionally, damaged stability for the self-propelled free running ship in following or head waves will be investigated.

\section{ACKNOWLEDGEMENTS}

The research was sponsored by the US Office of Naval Research (ONR) grant 000141-41-04-6-5 and ONR Global as part of the Naval International Cooperative Opportunities in Science and Technology Program (NICOP) under the supervisions of Drs. Ki-Han Kim and Woei-Min Lin. The CFD simulations were conducted utilizing DoD HPC. 


\section{REFERENCES}

Gao, Q., Vassalos, D., (2011), "Numerical study of the roll decay of intact and damaged ships", In: 12th STAB workshop, Washington, US.

Gao, Z., Gao, Q., Vassalos, D., (2011), "Numerical simulation of flooding of a damaged ship”, Ocean Engineering, Vol 38(14-15), pp. 1649-1662.

Gao, Z., Gao, Q., Vassalos, D., (2013), "Numerical study of damaged ship flooding in beam seas”, Ocean Engineering, Vol 61, pp. 77-87.

Huang J., Carrica P., Stern F., (2008), “Semi-coupled air/water immersed boundary approach for curvilinear dynamic overset grids with application to ship hydrodynamics", International Journal Numerical Methods Fluids, Vol. 58, pp. 591624.

Irvine, M., Longo, J., Stern, F., (2013), “Forward Speed Calm Water Roll Decay for Surface Combatant 5415: Global and Local Flow Measurements”, Journal of Ship Research, Vol. 57 (4), pp. 202-219.

ITTC, (2002), “The Specialist Committee on Prediction of Extreme Ship Motions and Capsizing”, Proceedings of 23rd International Towing Tank Conference, Venice, 2002.

Lee S., You J.M, Lee H.H., Lim T., Park S.T., Seo J., Rhee S.H., and Rhee K.P., (2015), “Experimental Study on the Six Degree-of-Freedom Motions of a Damaged Ship Floating in Regular Waves”, IEEE Journal of Oceanic Engineering, DOI:10.1109/JOE.2015.2390751.

Lee S., You J.M, Lee H.H., Lim T., Rhee S.H., and Rhee K.P., (2012), "Preliminary Tests of a Damaged Ship for CFD Validation”, International Journal of Naval Architecture and Ocean Engineering, Vol. 4, No. 2, pp.172-181.

Lim, T., Seo, J., Park, S.T., Rhee, S.H., (2014), "Experimental Study on the Safe-Return-to-Port of a Damaged Ship in Head Seas", 30th SNH, Hobart, Australia.

Palazzi, L., De Kat, J. O., (2004). "Model experiments and simulations of a damaged ship with air flow taken into account”, Marine Technology, 41(1), pp. 38-44.

Papanikolaou, A., Zaraphonitis, G., Spanos, D., Boulougouris, E., Eliopoulou, E., (2000). "Investigation into the capsizing of damaged Ro- Ro passenger ships in waves", Proc. of the 7th Intl Conf on Stability of Ships and Ocean Vehicles, STAB2000, Tasmania, pp. 351-362.

Sadat Hosseini, H., Stern, F., Olivieri, A., Campana, E., Hashimoto, H., Umeda, N., Bulian, G., Francescutto, A., (2010), “Head-waves Parametric Rolling of a Surface Combatant”, Ocean Engineering, Vol. 37, Issue 10, Pages 859-878.

Stern, F., Wilson, R.V., Coleman, H.W., and Paterson, E.G., (2001), “Comprehensive Approach to Verification and 
Validation of CFD Simulations_-Part 1: Methodology and Procedures”, ASME J. Fluids Eng., 123(4), pp. $793-802$.

Strasser, C., Jasionowski, A., Vassalos, D., (2009), "Calculation of the time-to-flood of a box shaped barge by using CFD”. In: 10th STAB conference, St. Petersburg, Russia.

Xing, T. and Stern, F., (2010), "Factors of Safety for Richardson Extrapolation”, ASME Journal of fluids engineering, Vol. 132, No. 6, DOI: 061403

\section{APPENDIX A (CALCULATION OF SOFT SPRING FORCES/MOMENTS)}

To calculate the total spring forces/moments, the displacement of each spring was found in earth coordinate system based on the position of the two ends of that spring. For the spring $i$, one end is attached to the ship at point $P_{i}$ and another is attached to the carriage at point $C_{i}$. The location of $P_{i}$ changes during simulation as it is located on the ship. The location of $P_{i}$ in earth coordinate system was found based on:

$$
r_{p_{i}}=r_{G}+R \cdot d_{p_{i}}
$$

Here, $r_{p_{i}}$ and $d_{p_{i}}$ are the displacement vector of $P_{i}$ in earth and ship coordinate system, $r_{G}$ is the displacement vector of $G$ in earth coordinate system, and $R$ is the rotational matrix from ship to earth coordinate system.

The force for the $i$-th spring attached to the ship at point $P_{i}$ and the carriage at $C_{i}$ was calculated as follows:

$$
F_{i}=\frac{r_{c_{i}}-r_{p_{i}}}{\left|r_{c_{i}}-r_{p_{i}}\right|} \cdot f\left(r_{c_{i}}-r_{p_{i}}\right)
$$

where, $F_{i}$ is the force vector in earth coordinate system induced by each spring and $f$ is the spring force function which is dependent on the spring displacement. In this study, the formula found from the experiment is used. 
The total spring induced forces in earth coordinate system $(\mathrm{F})$ are the sum of the forces induced by each spring as shown in Eq. (3). Then the total forces were transformed into the ship coordinate system (Eq. (4)).

$$
\begin{gathered}
\mathrm{F}=\sum_{i=1}^{4} F_{i} \\
F^{\prime}=R^{-1} \cdot F
\end{gathered}
$$

where $F^{\prime}$ is the total spring induced forces in the ship coordinate system.

For the spring moments, each spring force was transformed to the ship coordinate system first (Eq. (5)) and then the moment induced by each spring was calculated by the cross product of the moments' arm and forces (Eq. (6)). The total spring moments are the sum of the moments induce by each spring force (Eq. (7)).

$$
\begin{aligned}
& F_{i}^{\prime}=R^{-1} \cdot F_{i} \\
& M_{i}^{\prime}=\left(r_{c_{i}}-r_{p_{i}}\right) \times F_{i}^{\prime} \\
& M^{\prime}=\sum_{i=1}^{4} M_{i}^{\prime}
\end{aligned}
$$


Table 1 The main particulars of SSRC

\begin{tabular}{l|l}
\hline Description & Particulars \\
\hline Ship Model & \\
\hline L [m] & 3 \\
B/L [-] & 0.143 \\
T/L [-] & 0.034 \\
Damage length [m] & 0.150 \\
LCG/L [-] & 0.520 \\
KG/L [-] & 0.032 \\
$\mathrm{k}_{\mathrm{xx}}[-]$ & $0.053\left(0.0501^{*}\right)$ \\
$\mathrm{k}_{\mathrm{yy}}[-]$ & 0.250 \\
$\mathrm{k}_{\mathrm{zz}}[-]$ & 0.250 \\
$\mathrm{f}_{\mathrm{z}, \theta}$ & $1.003 \mathrm{~Hz}$ \\
$\mathrm{f}_{\phi}$ & $0.487 \mathrm{~Hz}$ \\
\hline Damaged Compartment & \\
\hline Number of Rooms & Two \\
Compartment shape & Box \\
Ventilation hole & Yes \\
Opening door shape & Rectangular \\
Opening door length & 0.0727 \\
Opening door height & 0.061 \\
\hline
\end{tabular}

*adjusted $\mathrm{k}_{\mathrm{xx}}$

Table 2 The EFD and CFD test matrix for SSRC

\begin{tabular}{|c|c|c|c|c|}
\hline Type & $\phi_{\mathrm{i}}(\mathrm{deg})$ & $\#$ of comp. room & sea condition & validation variables \\
\hline Flooding & 0.0 & - & Calm water & $\phi, \zeta_{A, B, C}$ \\
\hline Intact roll decay & $\begin{array}{l}-13.7 \\
-20.5\end{array}$ & - & Calm water & $\phi$ \\
\hline Damaged roll decay & $\begin{array}{c}-15.6 \\
15.9 \\
-25.5 \\
26.7 \\
-28.6 \\
\end{array}$ & $\begin{array}{l}1 \\
1 \\
1 \\
1 \\
2 \\
\end{array}$ & Calm water & $\begin{array}{|ll|}\phi & \\
\phi & \\
\phi, & \zeta_{A, B, C} \\
\phi & \\
\phi, & \zeta_{A, B, C, D, E} \\
\end{array}$ \\
\hline Intact beam waves* & - & 2 & $\begin{array}{l}\lambda / \mathrm{L}=0.52,1.17,1.99,2.20,2.42 \\
\mathrm{H} / \lambda=1 / 60,1 / 100\end{array}$ & $\mathrm{x}, \mathrm{y}, \mathrm{z}, \phi, \theta, \psi$ \\
\hline Damaged beam waves* & - & 2 & $\begin{array}{l}\lambda / L=0.52,1.17,1.99,2.20,2.42 \\
H / \lambda=1 / 60,1 / 100\end{array}$ & $\mathrm{x}, \mathrm{y}, \mathrm{z}, \phi, \theta, \psi, \zeta_{A, B, C, D, E}$ \\
\hline
\end{tabular}

*CFD simulations in waves are only conducted for $\mathrm{H} / \lambda=1 / 60$. 
Table 3 CFD and EFD comparison of roll motion for calm water cases

\begin{tabular}{|c|c|c|c|c|c|c|c|c|c|c|c|c|c|c|c|c|}
\hline \multirow{2}{*}{ Type } & \multirow{2}{*}{$\begin{array}{l}\phi_{\mathrm{i}} \\
(\mathrm{deg})\end{array}$} & \multirow{2}{*}{ EFD/CFD } & \multicolumn{3}{|c|}{$\mathrm{f}_{\mathrm{d}}(\mathrm{Hz})$} & \multicolumn{3}{|c|}{$\delta$} & \multicolumn{3}{|c|}{$\alpha$} & \multirow{2}{*}{\begin{tabular}{|l}
$\bar{\phi}$ \\
$(\mathrm{deg})$
\end{tabular}} & \multicolumn{3}{|c|}{$\phi_{\mathrm{m}}(\operatorname{deg})$} & \multirow[t]{2}{*}{ Ave. } \\
\hline & & & $\mathrm{p}^{*}$ & $\mathrm{~s}^{* *}$ & Ave. & $\mathrm{p}$ & $\mathrm{s}$ & Ave. & $\mathrm{p}$ & $\mathrm{s}$ & Ave. & & $\mathrm{p}$ & $\mathrm{s}$ & Ave. & \\
\hline \multirow{3}{*}{ Flooding } & & EFD & 0.452 & 0.439 & 0.446 & 0.083 & 0.201 & \begin{tabular}{|l|}
0.142 \\
\end{tabular} & 0.037 & 0.088 & 0.063 & -2.489 & 0.93 & 0.81 & 0.87 & \\
\hline & & CFD & 0.436 & 0.433 & \begin{tabular}{|l|}
0.435 \\
\end{tabular} & 0.042 & 0.122 & 0.082 & 0.018 & 0.053 & 0.036 & -2.472 & 2.68 & 2.58 & 2.63 & \\
\hline & & E\%D & 3.54 & 1.37 & 2.47 & 49.40 & 39.30 & 42.25 & 51.35 & 39.77 & 43.20 & \begin{tabular}{|l|}
0.68 \\
\end{tabular} & -188.17 & \begin{tabular}{|c|}
-218.52 \\
\end{tabular} & -202.30 & 65.78 \\
\hline \multirow{7}{*}{$\begin{array}{l}\text { Intact } \\
\text { Roll Decay }\end{array}$} & \multirow{3}{*}{-13.7} & EFD & 0.489 & 0.488 & 0.489 & 0.181 & 0.193 & 0.187 & 0.089 & 0.094 & \begin{tabular}{|l|l|}
0.092 \\
\end{tabular} & 0 & 8.24 & 9.25 & $\begin{array}{l}8.75 \\
\end{array}$ & \\
\hline & & CFD & 0.486 & 0.487 & 0.487 & 0.120 & 0.096 & \begin{tabular}{|l|}
0.108 \\
\end{tabular} & 0.058 & 0.057 & 0.058 & 0 & 9.14 & 9.1 & 9.12 & \\
\hline & & E\%D & 0.61 & 0.20 & 0.41 & 33.70 & 50.26 & 42.25 & 34.83 & 39.36 & 37.16 & 0.00 & -10.92 & 1.62 & -4.29 & 19.04 \\
\hline & \multirow{3}{*}{-20.5} & EFD & 0.493 & 0.492 & 0.493 & 0.267 & 0.241 & 0.254 & 0.132 & 0.119 & 0.126 & 0 & 12.48 & 11.81 & 12.15 & \\
\hline & & CFD & 0.490 & 0.488 & 0.489 & 0.242 & 0.187 & 0.215 & 0.119 & 0.091 & 0.105 & 0 & 13.18 & 11.73 & 12.46 & \\
\hline & & E\%D & 0.61 & 0.81 & 0.71 & 9.36 & 22.41 & \begin{tabular}{|l|}
15.55 \\
\end{tabular} & 9.85 & 23.53 & 16.33 & 0.00 & \begin{tabular}{|l|}
-5.61 \\
\end{tabular} & (0.68 & -2.55 & 8.16 \\
\hline & \multicolumn{2}{|c|}{ Ave. E\%D } & 0.61 & 0.51 & 0.56 & 21.53 & 36.33 & \begin{tabular}{|l|}
28.90 \\
\end{tabular} & 22.34 & 31.45 & 26.75 & 0.00 & 8.27 & 1.15 & 110.19 & 13.60 \\
\hline \multirow{16}{*}{$\begin{array}{l}\text { Damaged } \\
\text { Roll Decay }\end{array}$} & \multirow{3}{*}{-15.7} & EFD & 0.438 & 0.441 & 0.440 & 0.391 & 0.159 & 0.275 & 0.171 & 0.070 & 0.121 & \begin{tabular}{|l|}
-2.897 \\
\end{tabular} & 5.74 & 10.39 & 8.07 & \\
\hline & & CFD & 0.444 & 0.442 & \begin{tabular}{|l|}
0.443 \\
\end{tabular} & 0.255 & 0.128 & \begin{tabular}{|l|}
0.192 \\
\end{tabular} & 0.114 & 0.057 & 0.086 & -2.480 & $\begin{array}{l}7.17 \\
\end{array}$ & 11.01 & 9.09 & \\
\hline & & E\%D & \begin{tabular}{l|l|}
-1.37 \\
\end{tabular} & $\begin{array}{r}-0.23 \\
\end{array}$ & \begin{tabular}{|c|}
-0.80 \\
\end{tabular} & \begin{tabular}{|l|}
34.78 \\
\end{tabular} & 19.50 & \begin{tabular}{|l|}
30.36 \\
\end{tabular} & 33.33 & 18.57 & 29.05 & \begin{tabular}{|l|}
14.39 \\
\end{tabular} & -24.91 & $\begin{array}{l}-5.97 \\
\end{array}$ & -12.71 & 17.13 \\
\hline & \multirow{3}{*}{15.9} & EFD & 0.438 & 0.437 & 0.438 & 0.336 & 0.193 & \begin{tabular}{|l|}
0.265 \\
\end{tabular} & 0.147 & 0.084 & 0.116 & -2.628 & 7.68 & 14.29 & 10.99 & \\
\hline & & CFD & 0.445 & 0.445 & \begin{tabular}{|l|}
0.445 \\
\end{tabular} & 0.241 & 0.170 & 0.206 & \begin{tabular}{|c|c|}
0.107 \\
\end{tabular} & 0.076 & 0.092 & -2.354 & 8.08 & \begin{tabular}{|l|}
13.93 \\
\end{tabular} & 11.01 & \\
\hline & & E\%D & $\begin{array}{l}-1.60 \\
\end{array}$ & -1.83 & \begin{tabular}{|c|}
-1.71 \\
\end{tabular} & 28.27 & 11.92 & \begin{tabular}{|l|}
22.31 \\
\end{tabular} & 27.21 & 9.52 & 20.78 & \begin{tabular}{|l|}
10.43 \\
\end{tabular} & \begin{tabular}{|l|}
-5.21 \\
\end{tabular} & 2.52 & -0.18 & \begin{tabular}{|l|}
11.04 \\
\end{tabular} \\
\hline & \multirow{3}{*}{-25.5} & EFD & 0.444 & 0.440 & 0.442 & 0.385 & 0.188 & \begin{tabular}{|l|}
0.287 \\
\end{tabular} & 0.171 & 0.083 & 0.127 & -2.932 & 11.07 & 14.61 & 12.84 & \\
\hline & & CFD & 0.432 & 0.444 & 0.438 & 0.363 & 0.233 & \begin{tabular}{|l|}
0.298 \\
\end{tabular} & 0.157 & 0.103 & 0.130 & -2.351 & 11.07 & 16.61 & 13.84 & \\
\hline & & E\%D & \begin{tabular}{|l|}
2.70 \\
\end{tabular} & $\begin{array}{l}-0.91 \\
\end{array}$ & \begin{tabular}{|l|}
0.90 \\
\end{tabular} & \begin{tabular}{|l|}
5.71 \\
\end{tabular} & $\begin{array}{l}-23.94 \\
\end{array}$ & \begin{tabular}{|l|}
-4.01 \\
\end{tabular} & 8.19 & -24.10 & $\begin{array}{l}-2.36 \\
\end{array}$ & \begin{tabular}{|l|}
19.82 \\
\end{tabular} & \begin{tabular}{l|}
0.00 \\
\end{tabular} & -13.69 & \begin{tabular}{|c|}
-7.79 \\
\end{tabular} & \begin{tabular}{|l|}
11.07 \\
\end{tabular} \\
\hline & \multirow{3}{*}{26.7} & EFD & 0.443 & 0.444 & 0.444 & 0.356 & 0.268 & \begin{tabular}{|l|}
0.312 \\
\end{tabular} & 0.157 & 0.119 & 0.138 & $\mid-2.474$ & 9.87 & 17.24 & 13.56 & \\
\hline & & CFD & 0.445 & 0.431 & 0.438 & 0.285 & 0.164 & 0.225 & 0.127 & 0.071 & 0.099 & \begin{tabular}{|l|}
-2.373 \\
\end{tabular} & 9.96 & 13.61 & 11.79 & \\
\hline & & E\%D & \begin{tabular}{|l|l|}
-0.45 \\
\end{tabular} & 2.93 & 1.24 & 19.94 & 38.81 & \begin{tabular}{|l|}
28.04 \\
\end{tabular} & 19.11 & 40.34 & 28.26 & \begin{tabular}{|l|}
4.08 \\
\end{tabular} & \begin{tabular}{|c|}
-0.91 \\
\end{tabular} & 21.06 & 13.06 & \begin{tabular}{|l|}
16.46 \\
\end{tabular} \\
\hline & \multirow{3}{*}{-28.6} & EFD & 0.434 & 0.432 & \begin{tabular}{|l|}
0.433 \\
\end{tabular} & 0.542 & 0.183 & \begin{tabular}{|l|}
0.363 \\
\end{tabular} & 0.235 & 0.079 & 0.157 & \begin{tabular}{|l}
-5.843 \\
\end{tabular} & \begin{tabular}{l|l|}
8.04 \\
\end{tabular} & 17.37 & 12.71 & \\
\hline & & CFD & 0.402 & 0.416 & \begin{tabular}{|l|}
0.409 \\
\end{tabular} & 0.439 & 0.184 & 0.312 & 0.176 & 0.077 & 0.127 & -4.995 & 9.66 & 16.95 & 13.31 & \\
\hline & & E\%D & $\begin{array}{l}7.37 \\
\end{array}$ & 3.70 & \begin{tabular}{|r|}
5.54 \\
\end{tabular} & \begin{tabular}{|c|}
19.00 \\
\end{tabular} & -0.55 & \begin{tabular}{|l|}
14.07 \\
\end{tabular} & 25.11 & 2.53 & $\mathbf{1 9 . 4 3}$ & 14.51 & -20.15 & 2.42 & -4.72 & \begin{tabular}{|l|}
10.67 \\
\end{tabular} \\
\hline & \multicolumn{2}{|c|}{\begin{tabular}{|l|} 
Ave. E\%D \\
\end{tabular}} & 2.70 & 1.92 & 2.04 & 21.54 & 18.94 & \begin{tabular}{|l|}
19.76 \\
\end{tabular} & 22.59 & 19.01 & 19.97 & 12.65 & 10.24 & 9.13 & 7.69 & \begin{tabular}{|l|l|}
13.28 \\
\end{tabular} \\
\hline
\end{tabular}

Table 4 CFD and EFD comparison of water height inside the compartment for calm water cases

\begin{tabular}{|c|c|c|c|c|c|c|c|c|c|c|c|c|c|c|}
\hline \multirow{2}{*}{ Type } & \multirow{2}{*}{$\phi_{\mathrm{i}}(\mathrm{deg})$} & \multirow{2}{*}{ EFD/CFD } & \multicolumn{2}{|c|}{$\zeta_{A}$} & \multicolumn{2}{|c|}{$\zeta_{\mathrm{B}}$} & \multicolumn{2}{|c|}{$\zeta_{C}$} & \multicolumn{2}{|c|}{$\zeta_{D}$} & $\zeta_{\mathrm{E}}$ & \multirow{2}{*}{\begin{tabular}{|l} 
Ave. \\
$\bar{\zeta}$
\end{tabular}} & \multirow{2}{*}{$\begin{array}{c}\text { Ave. } \\
\mathrm{f}_{\zeta}\end{array}$} & \multirow[t]{2}{*}{ Ave. } \\
\hline & & & $\overline{\bar{\zeta}_{A}(\mathrm{~m})}$ & $\mathrm{f}_{\zeta_{A}}(\mathrm{~Hz})$ & $\overline{\bar{\zeta}_{\mathrm{B}}(\mathrm{m})}$ & $\mathrm{f}_{\zeta_{\mathrm{B}}}(\mathrm{Hz})$ & $\overline{\bar{\zeta}_{\mathrm{C}}(\mathrm{m})}$ & $\mathrm{f}_{\zeta_{\mathrm{C}}}(\mathrm{Hz})$ & $\overline{\bar{\zeta}_{D}}(\mathrm{~m})$ & $\mathrm{f}_{\zeta_{\mathrm{D}}}(\mathrm{Hz})$ & \begin{tabular}{|l|l|}
$\bar{\zeta}_{\mathrm{E}}(\mathrm{m})$ & $\mathrm{f}_{\zeta_{\mathrm{E}}}(\mathrm{Hz})$ \\
\end{tabular} & & & \\
\hline \multirow{3}{*}{ Flooding } & \multirow{3}{*}{0} & EFD & \begin{tabular}{|l|}
0.080 \\
\end{tabular} & 0.465 & $\begin{array}{l}0.071 \\
\end{array}$ & 0.441 & \begin{tabular}{|l|}
0.064 \\
\end{tabular} & 0.465 & \multirow{3}{*}{\multicolumn{2}{|c|}{ no comp. \#2 }} & \multirow{3}{*}{ no comp. \#2 } & & & \\
\hline & & CFD & 0.078 & 0.444 & 0.071 & 0.435 & 0.064 & 0.424 & & & & & & \\
\hline & & E\%D & 2.55 & 4.47 & 0.81 & 1.33 & -0.39 & 8.74 & & & & 1.25 & 4.85 & 3.05 \\
\hline \multirow{6}{*}{$\begin{array}{l}\text { Damaged Roll } \\
\text { Decay }\end{array}$} & \multirow{3}{*}{-25.5} & EFD & 0.073 & 0.428 & 0.064 & \multirow{3}{*}{ N/A } & 0.055 & 0.437 & \multirow{3}{*}{\multicolumn{2}{|c|}{ no comp. $\# 2$}} & \multirow{3}{*}{ no comp. \#2 } & & & \\
\hline & & CFD & 0.074 & 0.415 & 0.068 & & 0.063 & 0.430 & & & & & & \\
\hline & & E\%D & -1.89 & 2.96 & -6.49 & & -13.44 & 1.62 & & & & 7.27 & 1.53 & $\mathbf{4 . 4 0}$ \\
\hline & \multirow{3}{*}{-28.6} & EFD & 0.089 & 0.446 & 0.062 & \multirow{3}{*}{$\mathrm{N} / \mathrm{A}$} & 0.059 & 0.426 & 0.089 & 0.440 & 0.077 & & & \\
\hline & & CFD & 0.086 & 0.402 & 0.072 & & 0.061 & 0.419 & 0.083 & 0.413 & 0.075 & & & \\
\hline & & E\%D & 3.67 & 9.99 & -16.27 & & -4.47 & 1.44 & 6.62 & 6.14 & 2.46 & 6.70 & 3.51 & 5.11 \\
\hline
\end{tabular}


Table 5 CFD and EFD comparison of $1 / 2,1^{\text {st }}$ and $2^{\text {nd }}$ harmonic amplitudes for intact SSRC in beam waves with $\mathrm{H} / \lambda=1 / 60$

\begin{tabular}{|c|c|c|c|c|c|c|c|c|c|c|c|c|c|c|c|c|c|}
\hline \multirow{2}{*}{\multicolumn{2}{|c|}{$\underline{\lambda / L}$}} & \multicolumn{3}{|l|}{0.52} & \multicolumn{3}{|l|}{1.17} & \multicolumn{3}{|l|}{1.99} & \multicolumn{3}{|l|}{2.2} & \multicolumn{3}{|l|}{2.42} & \multirow[b]{2}{*}{ Ave E\%D } \\
\hline & & \begin{tabular}{|l|l|} 
EFD \\
\end{tabular} & CFD & E\%D & EFD & CFD & E\%D & EFD & CFD & E\%D & EFD & CFD & E\%D & EFD & CFD & E\%D & \\
\hline \multirow{7}{*}{$1 \mathrm{st}$} & $\mathrm{x} / \mathrm{A}$ & 0.030 & 0.034 & \begin{tabular}{|l|l|}
4 \\
\end{tabular} & 0.021 & 0.029 & -42 & 0.017 & 0.010 & 39 & 0.025 & 0.016 & 35 & 0.013 & 0.015 & \begin{tabular}{|r|}
-14 \\
\end{tabular} & 29 \\
\hline & $\mathrm{y} / \mathrm{A}$ & 0.533 & 0.525 & 1 & 0.673 & 0.843 & -25 & 1.253 & 0.864 & 31 & 1.349 & 0.935 & 31 & 0.994 & 0.965 & 3 & 18 \\
\hline & Z/A & 0.936 & 1.530 & -63 & 1.030 & 1.081 & -5 & 0.853 & 0.893 & -5 & 0.772 & 0.987 & -28 & 0.728 & 0.978 & -34 & 27 \\
\hline & $\varphi / \mathrm{Ak}$ & 0.121 & 0.201 & -66 & 0.548 & 0.354 & 35 & 4.786 & 4.720 & 1 & 6.297 & 5.543 & 12 & 5.643 & 5.038 & 11 & 25 \\
\hline & $\theta / \mathrm{Ak}$ & 0.022 & 0.011 & 49 & 0.007 & 0.030 & -306 & 0.049 & 0.016 & 67 & 0.074 & 0.014 & 82 & 0.063 & 0.014 & 78 & 116 \\
\hline & $\Psi / \mathrm{Ak}$ & 0.005 & 0.005 & -1 & 0.009 & 0.019 & -101 & 0.029 & 0.047 & -61 & 0.046 & 0.056 & -21 & 0.034 & 0.050 & -48 & 46 \\
\hline & Avg. E\%D & & & 32 & & & 86 & & & 34 & & & 35 & & & 31 & 44 \\
\hline \multirow{7}{*}{ 2nd } & $\mathrm{x} / \mathrm{A}$ & 0.002 & 0.000 & 92 & 0.001 & 0.000 & 77 & 0.004 & 0.021 & -458 & 0.011 & 0.000 & 95 & 0.008 & 0.000 & 95 & 163 \\
\hline & $\mathrm{y} / \mathrm{A}$ & 0.003 & 0.011 & -225 & 0.006 & 0.012 & -121 & 0.027 & 0.057 & -111 & 0.119 & 0.009 & 92 & 0.109 & 0.006 & 94 & 129 \\
\hline & Z/A & 0.001 & 0.024 & -3895 & 0.007 & 0.010 & -47 & 0.201 & 0.059 & 71 & 0.150 & 0.017 & 89 & 0.168 & 0.006 & 96 & 840 \\
\hline & $\varphi / \mathrm{Ak}$ & 0.003 & 0.027 & -846 & 0.018 & 0.017 & 2 & 0.045 & 0.102 & -128 & 0.027 & 0.057 & -110 & 0.114 & 0.073 & 36 & 224 \\
\hline & $\theta / \mathrm{Ak}$ & 0.000 & 0.002 & -1300 & 0.002 & 0.000 & 94 & 0.016 & 0.011 & 32 & 0.015 & 0.002 & 89 & 0.007 & 0.004 & 41 & 311 \\
\hline & $\Psi / \mathrm{Ak}$ & 0.001 & 0.000 & 92 & 0.001 & 0.000 & 71 & 0.010 & 0.009 & 11 & 0.009 & 0.001 & 94 & 0.002 & 0.001 & 16 & 57 \\
\hline & Avg. E\%D & & & 1075 & & & 69 & & & 135 & & & 95 & & & 63 & 287 \\
\hline \multirow{7}{*}{$1 / 2$} & $\mathrm{x} / \mathrm{A}$ & 0.032 & 0.010 & 67 & 0.013 & 0.001 & 91 & 0.005 & 0.001 & 86 & 0.012 & 0.000 & 97 & 0.005 & 0.002 & 53 & 79 \\
\hline & $\mathrm{y} / \mathrm{A}$ & 5.602 & 0.565 & 90 & 0.004 & 0.036 & -785 & 0.007 & 0.007 & 0 & 0.012 & 0.033 & -178 & 0.117 & 0.007 & 94 & 229 \\
\hline & z/A & 0.599 & 0.047 & 92 & 0.022 & 0.020 & 9 & 0.029 & 0.005 & 83 & 0.100 & 0.015 & 85 & 0.053 & 0.008 & 84 & 71 \\
\hline & $\varphi / \mathrm{Ak}$ & 5.777 & 7.186 & -24 & 0.007 & 0.148 & -2016 & 0.044 & 0.184 & -319 & 0.056 & 0.092 & -64 & 0.719 & 0.073 & 90 & 503 \\
\hline & $\theta / \mathrm{Ak}$ & 0.069 & 0.002 & 97 & 0.007 & 0.002 & 75 & 0.002 & 0.001 & 48 & 0.010 & 0.000 & 96 & 0.009 & 0.001 & 91 & 81 \\
\hline & $\Psi / \mathrm{Ak}$ & 0.058 & 0.044 & 23 & 0.001 & 0.005 & -327 & 0.002 & 0.009 & -475 & 0.003 & 0.002 & 50 & 0.002 & 0.004 & -96 & 194 \\
\hline & Avg. E\%D & & & 66 & & & 550 & & & 169 & & & 95 & & & 85 & 193 \\
\hline \multicolumn{2}{|c|}{ Avg. E\%D } & & & 391 & & & 235 & & & 113 & & & 75 & & & 60 & 175 \\
\hline
\end{tabular}

Table 6 CFD and EFD comparison of $1 / 2,1^{\text {st }}$ and $2^{\text {nd }}$ harmonic amplitudes for damaged SSRC in beam waves with $\mathrm{H} / \lambda=1 / 60$

\begin{tabular}{|c|c|c|c|c|c|c|c|c|c|c|c|c|c|c|c|c|c|}
\hline \multirow[t]{2}{*}{$\underline{\lambda / \mathbf{L}}$} & & \multicolumn{3}{|l|}{0.52} & \multicolumn{3}{|l|}{1.17} & \multicolumn{3}{|l|}{1.99} & \multicolumn{3}{|l|}{2.2} & \multicolumn{3}{|l|}{2.42} & \multirow[b]{2}{*}{ Ave E\%D } \\
\hline & & EFD & CFD & E\%D & EFD & CFD & E\%D & EFD & CFD & E\%D & EFD & CFD & E\%D & EFD & CFD & E\%D & \\
\hline \multirow{7}{*}{1 st } & $\mathrm{x} / \mathrm{A}$ & 0.027 & 0.040 & -49 & 0.022 & 0.023 & -7 & 0.015 & 0.021 & -40 & 0.011 & \begin{tabular}{|l|}
0.017 \\
\end{tabular} & -55 & 0.004 & 0.015 & -298 & 90 \\
\hline & $y / A$ & 0.399 & 0.646 & -62 & 0.573 & 0.832 & -45 & 0.731 & 0.852 & -17 & 1.017 & 0.903 & 11 & 1.094 & 1.053 & 4 & 28 \\
\hline & z/A & 1.069 & 1.416 & -32 & 0.966 & 1.016 & -5 & 0.856 & 1.032 & -21 & 0.810 & 1.088 & -34 & \begin{tabular}{|l|}
0.859 \\
\end{tabular} & 1.085 & -26 & 24 \\
\hline & $\phi / \mathrm{Ak}$ & 0.140 & 0.288 & -106 & 0.391 & 0.572 & -46 & 2.033 & 1.092 & 46 & 4.520 & 4.388 & 3 & 5.539 & 5.162 & 7 & 42 \\
\hline & $\theta / \mathrm{Ak}$ & 0.025 & 0.033 & -31 & 0.013 & 0.021 & -60 & 0.013 & 0.021 & -66 & 0.045 & 0.013 & 71 & 0.065 & 0.008 & 87 & 63 \\
\hline & $\Psi / \mathrm{Ak}$ & 0.010 & 0.010 & -3 & 0.009 & 0.009 & -1 & 0.019 & 0.022 & -15 & 0.029 & 0.042 & -45 & 0.038 & 0.053 & -40 & 21 \\
\hline & Avg. E\%D & & & 47 & & & 27 & & & 34 & & & 37 & & & 77 & $\overline{44}$ \\
\hline \multirow{7}{*}{ 2nd } & $\mathrm{x} / \mathrm{A}$ & 0.005 & 0.000 & 93 & 0.002 & 0.001 & 65 & 0.009 & 0.002 & 75 & 0.003 & 0.000 & 91 & 0.007 & 0.001 & 91 & 83 \\
\hline & $\mathrm{y} / \mathrm{A}$ & 0.004 & 0.004 & 10 & 0.011 & 0.019 & -73 & 0.049 & 0.059 & -20 & 0.070 & 0.018 & 75 & 0.119 & 0.005 & 96 & 55 \\
\hline & z/A & 0.009 & 0.013 & -36 & 0.011 & 0.017 & -49 & 0.126 & 0.008 & 94 & 0.176 & 0.023 & 87 & 0.229 & 0.054 & 76 & 68 \\
\hline & $\phi / \mathrm{Ak}$ & 0.000 & 0.038 & -9263 & 0.015 & 0.109 & -603 & 0.066 & 0.083 & -26 & 0.276 & 0.161 & 42 & 0.036 & 0.253 & -603 & 2107 \\
\hline & $\theta / \mathrm{Ak}$ & 0.001 & 0.000 & 35 & 0.000 & 0.003 & -809 & 0.000 & 0.000 & -49 & 0.013 & 0.001 & 89 & 0.007 & 0.002 & 71 & 211 \\
\hline & $\Psi / \mathrm{Ak}$ & 0.000 & 0.000 & -35 & 0.001 & \begin{tabular}{|l|}
0.002 \\
\end{tabular} & -24 & 0.004 & 0.003 & 23 & 0.014 & 0.000 & 97 & 0.004 & 0.004 & 1 & 36 \\
\hline & Avg. E\%D & & & 1579 & & & 271 & & & 48 & & & 80 & & & 156 & 427 \\
\hline \multirow{7}{*}{$1 / 2$} & $\mathrm{x} / \mathrm{A}$ & 0.034 & 0.001 & 97 & 0.021 & 0.001 & 96 & 0.009 & 0.012 & -29 & 0.002 & 0.000 & 78 & 0.003 & 0.001 & 78 & 76 \\
\hline & $\mathrm{y} / \mathrm{A}$ & 0.505 & 0.016 & 97 & 0.053 & 0.046 & 13 & 0.035 & 0.065 & -84 & 0.070 & 0.085 & -22 & 0.006 & 0.016 & -188 & 81 \\
\hline & z/A & 0.116 & 0.045 & 61 & 0.064 & \begin{tabular}{|l|} 
\\
\end{tabular} & 40 & 0.030 & 0.018 & 40 & 0.066 & 0.035 & 48 & 0.063 & 0.013 & 80 & 54 \\
\hline & $\phi / A k$ & 0.558 & 0.245 & 56 & 0.126 & 0.699 & -456 & 0.143 & 0.425 & -196 & 0.326 & 0.491 & -51 & 0.027 & 0.301 & -1019 & 356 \\
\hline & $\theta / \mathrm{Ak}$ & 0.008 & 0.001 & 86 & 0.004 & 0.002 & 40 & 0.004 & 0.000 & 89 & 0.007 & 0.001 & 79 & 0.002 & 0.001 & 23 & 63 \\
\hline & $\Psi / \mathrm{Ak}$ & 0.010 & 0.000 & 98 & 0.005 & 0.009 & -72 & 0.002 & 0.024 & -1391 & 0.004 & 0.005 & -10 & 0.002 & 0.018 & -665 & 447 \\
\hline & Avg. E\%D & & & 82 & & & 120 & & & 305 & & & 48 & & & 342 & 179 \\
\hline \multicolumn{2}{|c|}{ Avg. E\%D } & & & 569 & & & 139 & & & 129 & & & 55 & & & 192 & 217 \\
\hline
\end{tabular}


Table 7 CFD and EFD comparison of water height inside the compartment for beam wave cases

\begin{tabular}{|c|c|c|c|c|c|c|c|c|c|c|c|c|c|c|c|c|c|c|c|}
\hline \multirow{2}{*}{ Type } & \multirow{2}{*}{$\lambda / \mathbf{L}$} & \multirow{2}{*}{ EFD/CFD } & \multicolumn{4}{|c|}{$\zeta_{\mathrm{A}}(\mathrm{m})$} & \multicolumn{4}{|c|}{$\zeta_{\mathrm{B}}(\mathrm{m})$} & \multicolumn{4}{|c|}{$\zeta_{C}(\mathrm{~m})$} & \multirow{2}{*}{$\begin{array}{c}\text { Ave. } \\
\bar{\zeta}\end{array}$} & \multirow{2}{*}{$\begin{array}{c}\text { Ave. } \\
\zeta_{1}\end{array}$} & \multirow{2}{*}{$\begin{array}{r}\text { Ave. } \\
\zeta_{2}\end{array}$} & \multirow{2}{*}{$\begin{array}{c}\text { Ave. } \\
\zeta_{1 / 2} \\
\end{array}$} & \multirow[t]{2}{*}{ Ave. } \\
\hline & & & $\bar{\zeta}_{A}$ & $\zeta_{\mathrm{A} 1}$ & $\zeta_{\mathrm{A} 2}$ & $\zeta_{\mathrm{A} 1 / 2}$ & $\bar{\zeta}_{\mathrm{B}}$ & $\zeta_{\mathrm{B} 1}$ & $\zeta_{\mathrm{B} 2}$ & $\zeta_{\mathrm{B} 1 / 2}$ & $\bar{\zeta}_{\mathrm{C}}$ & $\zeta_{\mathrm{C} 1}$ & $\zeta_{\mathrm{C} 2}$ & $\zeta_{\mathrm{C} 1 / 2}$ & & & & & \\
\hline \multirow{9}{*}{$\begin{array}{l}\text { Damaged } \\
\text { beam } \\
\text { waves }\end{array}$} & & EFD & 0.079 & 0.017 & 0.007 & 0.005 & 0.069 & 0.002 & 0.006 & 0.001 & 0.065 & 0.016 & 0.006 & 0.007 & & & & & \\
\hline & 0.52 & CFD & 0.076 & 0.023 & 0.008 & 0.002 & 0.069 & 0.002 & 0.009 & 0.000 & 0.067 & 0.022 & \begin{tabular}{|l|l|}
0.008 \\
\end{tabular} & 0.002 & & & & & \\
\hline & & E\%D & 3.05 & \begin{tabular}{|l|}
-34.74 \\
\end{tabular} & -10.63 & 63.96 & -0.31 & -64.75 & -50.07 & 62.16 & -3.22 & \begin{tabular}{|l|}
-39.41 \\
\end{tabular} & $\mid-24.89$ & 63.71 & 2.20 & 46.30 & 28.53 & 63.28 & 35.08 \\
\hline & & EFD & 0.077 & 0.050 & 0.003 & 0.007 & 0.067 & 0.002 & 0.005 & 0.000 & 0.060 & 0.052 & \begin{tabular}{|l|}
0.007 \\
\end{tabular} & 0.006 & & & & & \\
\hline & 2.20 & CFD & 0.086 & 0.047 & 0.008 & \begin{tabular}{|l|}
0.005 \\
\end{tabular} & 0.069 & 0.006 & 0.002 & 0.001 & 0.063 & \begin{tabular}{|l|}
0.051 \\
\end{tabular} & \begin{tabular}{|l|}
0.007 \\
\end{tabular} & \begin{tabular}{|l|}
0.005 \\
\end{tabular} & & & & & \\
\hline & & E\%D & -10.45 & 4.28 & \begin{tabular}{|l|}
-189.37 \\
\end{tabular} & 26.95 & -4.06 & -261.22 & 61.63 & -53.63 & -5.08 & \begin{tabular}{|l|}
3.41 \\
\end{tabular} & 6.34 & 29.23 & 6.53 & 89.63 & 85.78 & 36.60 & 54.64 \\
\hline & & EFD & 0.074 & 0.055 & 0.002 & 0.003 & 0.066 & 0.004 & 0.006 & 0.000 & 0.064 & \begin{tabular}{|l|l|} 
& 0.057 \\
\end{tabular} & \begin{tabular}{|l|}
0.008 \\
\end{tabular} & 0.004 & & & & & \\
\hline & 2.42 & CFD & 0.078 & 0.060 & 0.009 & 0.000 & 0.066 & 0.011 & 0.004 & 0.001 & 0.067 & 0.056 & \begin{tabular}{|l|}
0.011 \\
\end{tabular} & 0.001 & & & & & \\
\hline & & E\%D & \begin{tabular}{|c|}
-5.38 \\
\end{tabular} & \begin{tabular}{|l|}
-8.35 \\
\end{tabular} & \begin{tabular}{|c|}
-377.56 \\
\end{tabular} & 92.59 & -0.31 & -189.50 & 38.89 & $\mid-119.14$ & -4.55 & \begin{tabular}{|l|}
1.93 \\
\end{tabular} & $|-36.41|$ & 82.16 & 3.41 & 66.59 & 150.9 & 97.96 & 79.73 \\
\hline
\end{tabular}



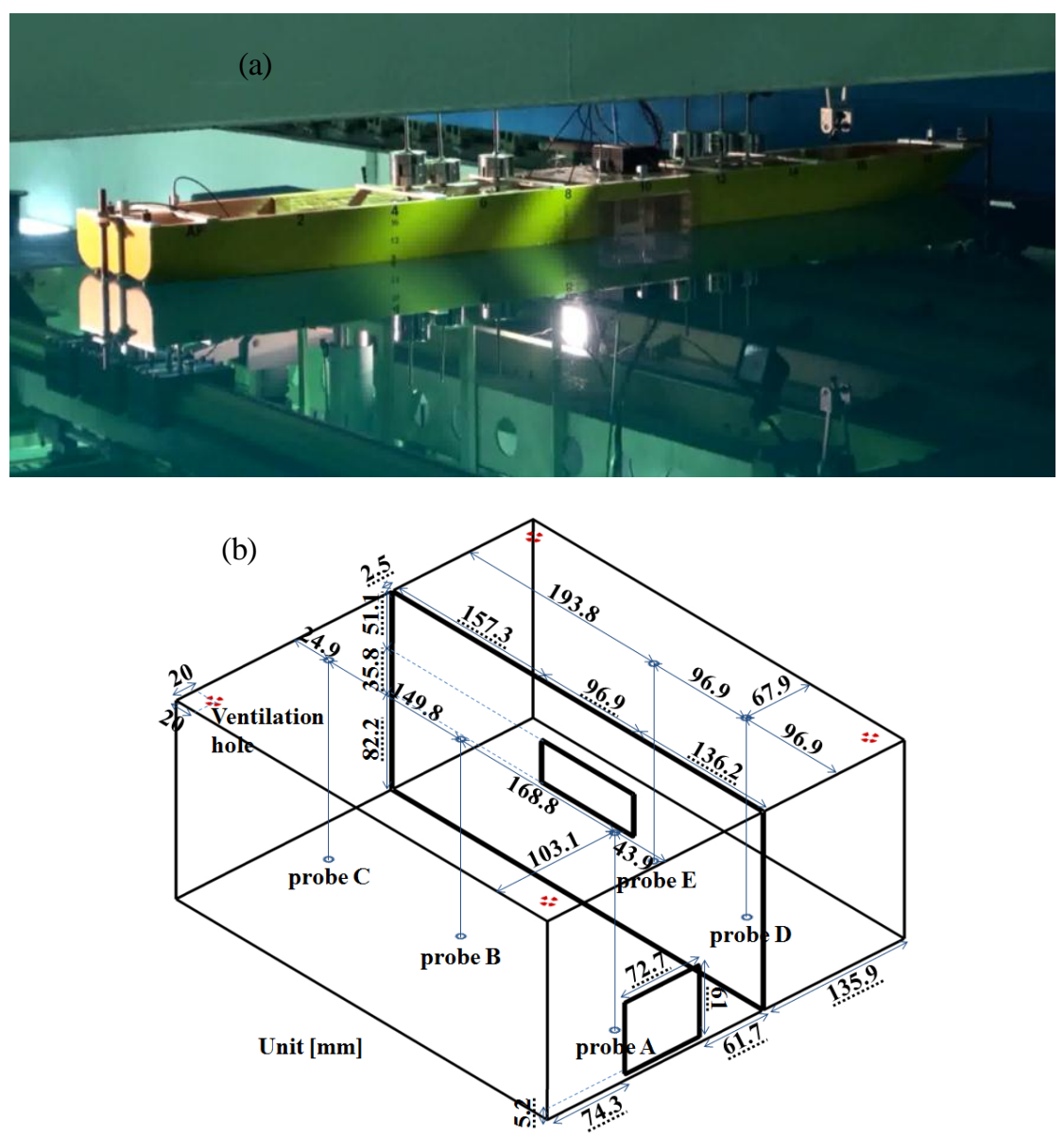

Figure 1 The damaged SSRC model: (a) SSRC hull geometry; (b) compartment layout. 


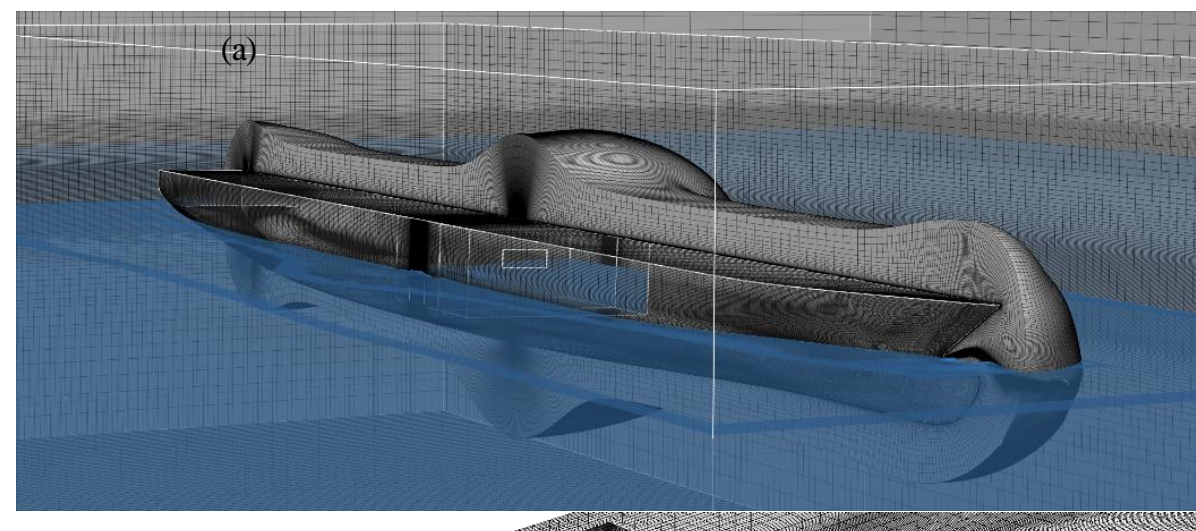

(b)

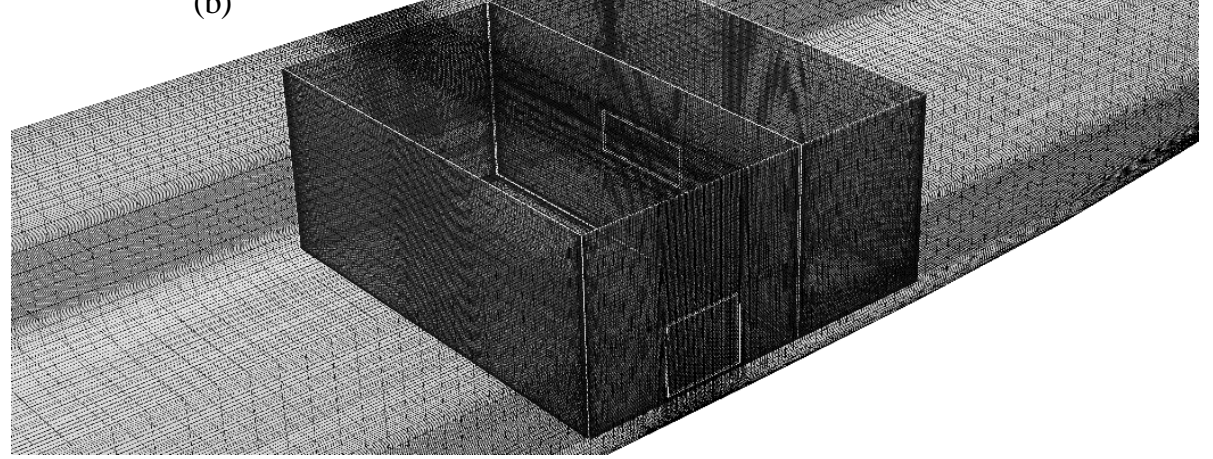

Figure 2 Grid topology for damaged SSRC: (a) Hull; (b) Compartment. 

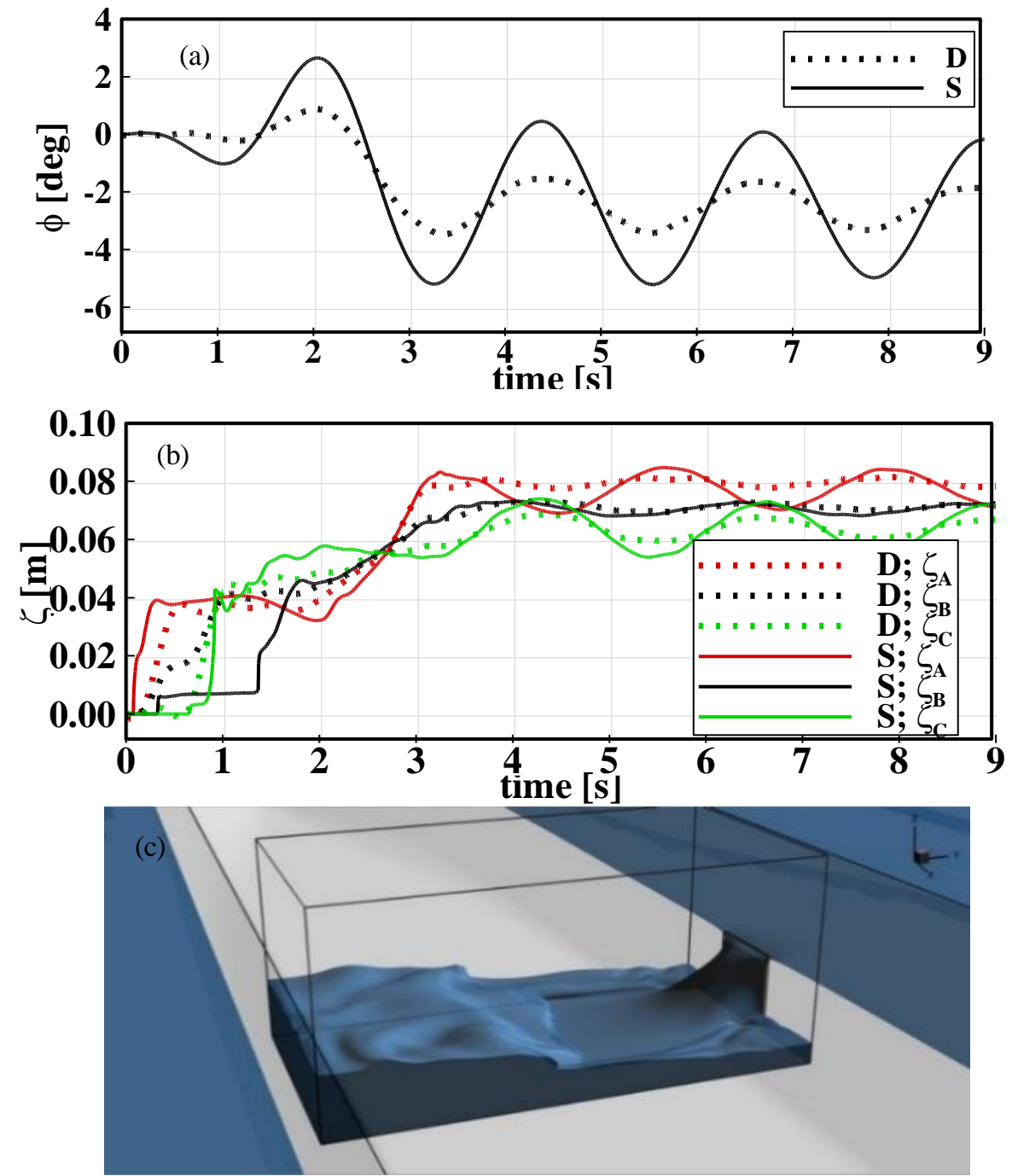

Figure 3 Flooding procedure comparison between experimental data (D) and simulation prediction (S) for damaged SSRC in calm water: (a) roll; (b) floodwater height; (c) a snap shot of compartment flooding for the simulation 

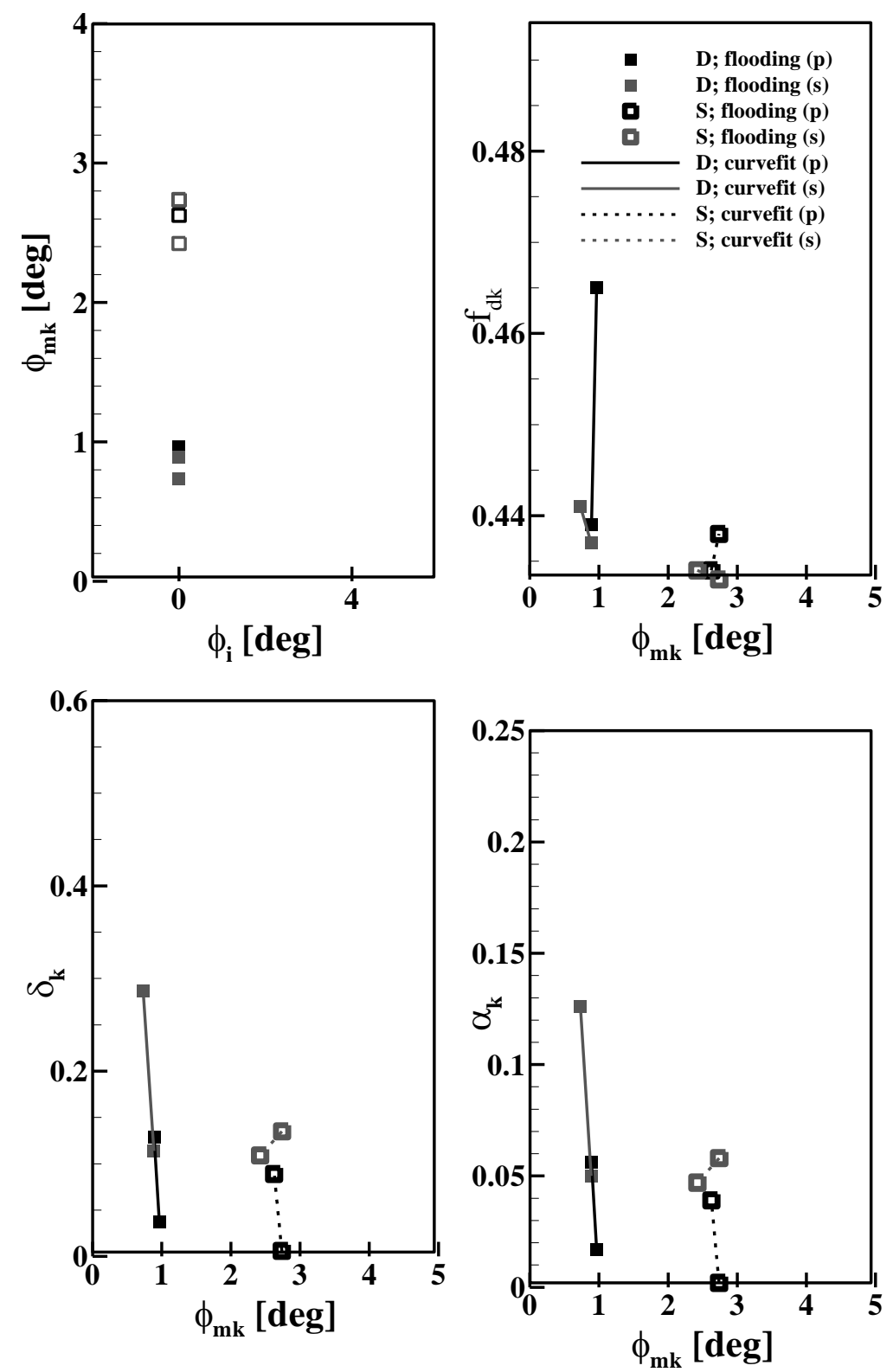

Figure 4 Experimental data and simulation prediction for variation of $\phi_{\mathrm{mk}}$ with respect to $\phi_{\mathrm{i}}$ and $\mathrm{f}_{\mathrm{dk}}, \delta_{\mathrm{k}}, \alpha_{\mathrm{k}}$ with respect to $\phi_{\mathrm{mk}}$ for flooding, calculated from roll peaks on portside (p) and starboard (s) 


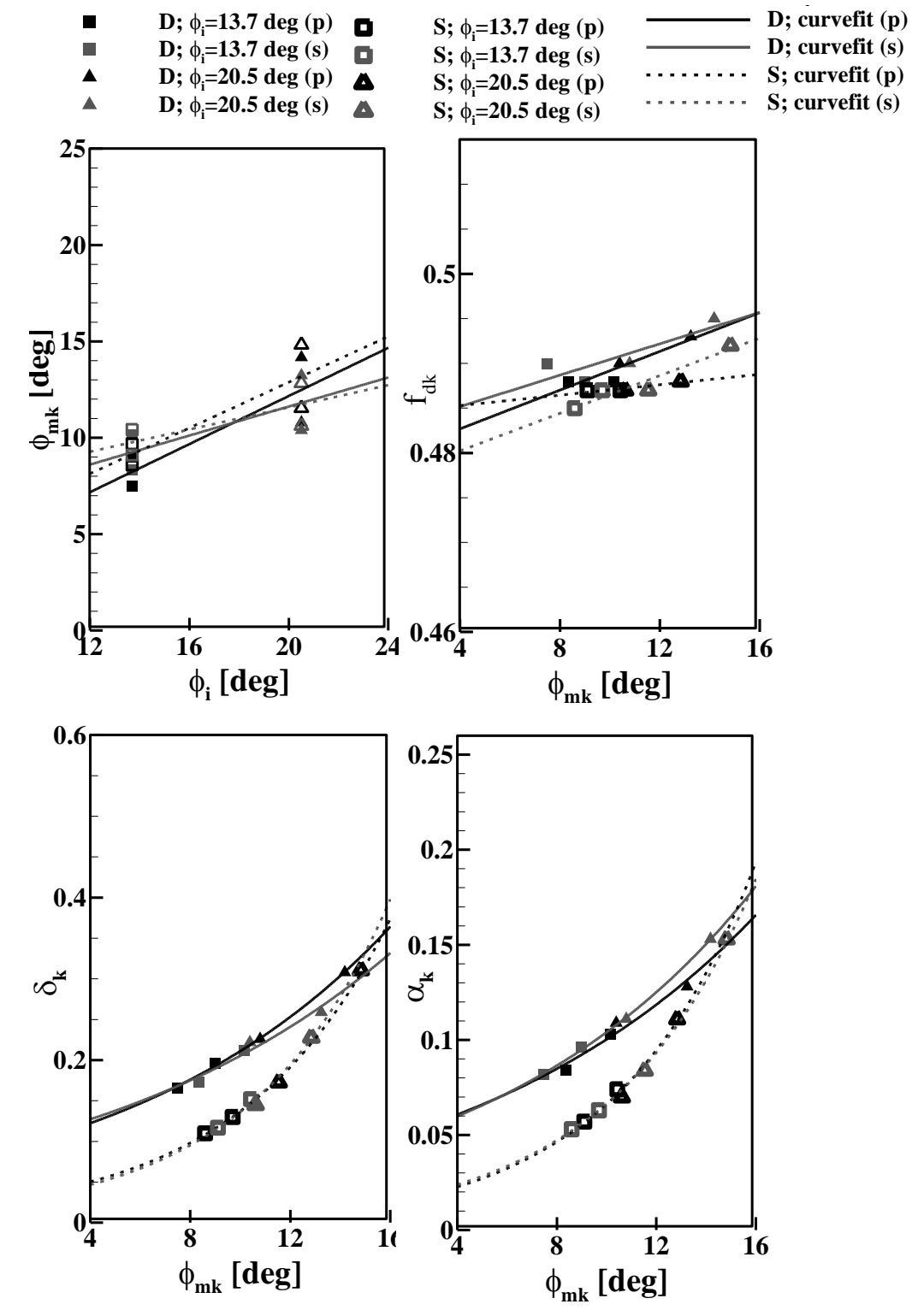

Figure 5 Experimental data and simulation prediction for variation of $\phi_{\mathrm{mk}}$ with respect to $\phi_{\mathrm{i}}$ and $\mathrm{f}_{\mathrm{dk}}, \delta_{\mathrm{k}}, \alpha_{\mathrm{k}}$ with respect to $\phi_{\mathrm{mk}}$ for intact roll decay, calculated from roll peaks on portside (p) and starboard (s) 

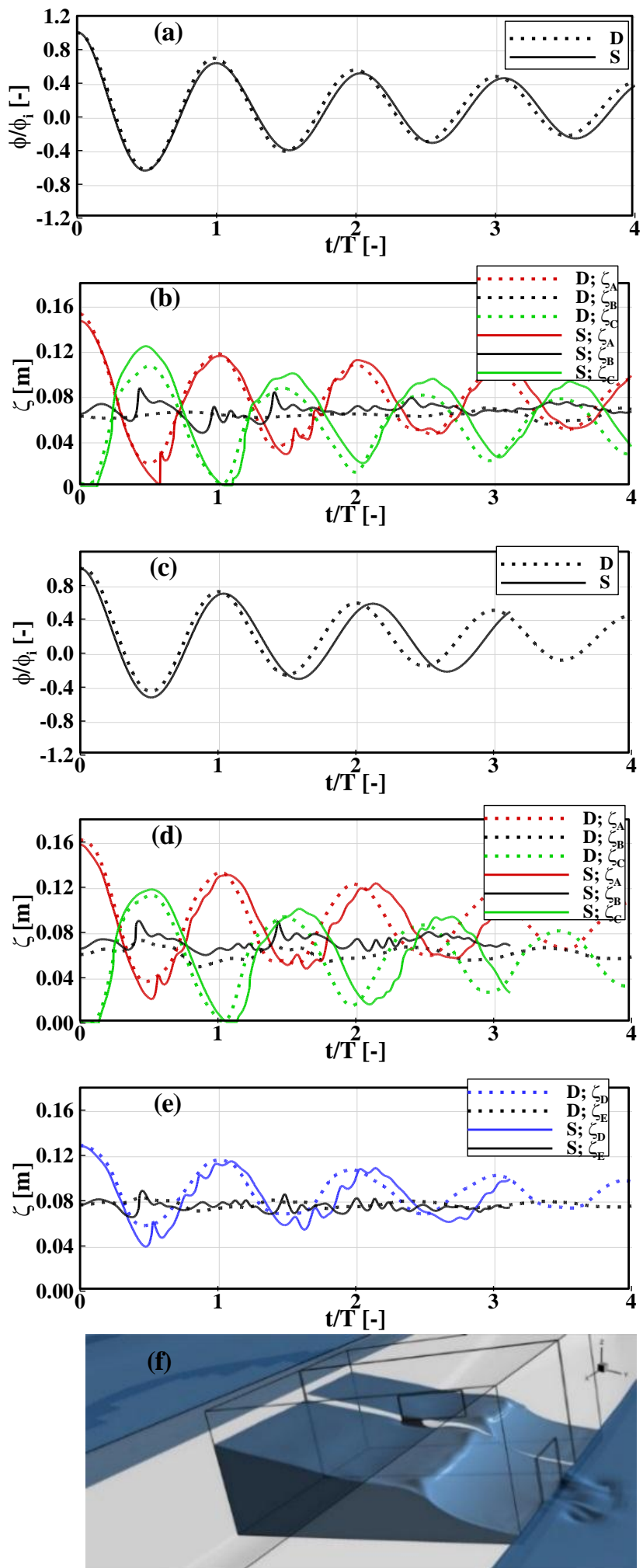

Figure 6 Experimental data and simulation prediction for damaged roll decay: (a) roll for $\phi_{\mathrm{i}}=-25.5^{\circ}$; (b) floodwater height for $\phi_{\mathrm{i}}=-25.5^{\circ}$; (c) roll for $\phi_{\mathrm{i}}=-28.6^{\circ}$; (d) floodwater height in room \#1for $\phi_{\mathrm{i}}=-28.6^{\circ}$; (e) floodwater height in room \#2 for $\phi_{\mathrm{i}}=-28.6^{\circ}$; (f) a snap shot of the predicted two-room compartment flooding 


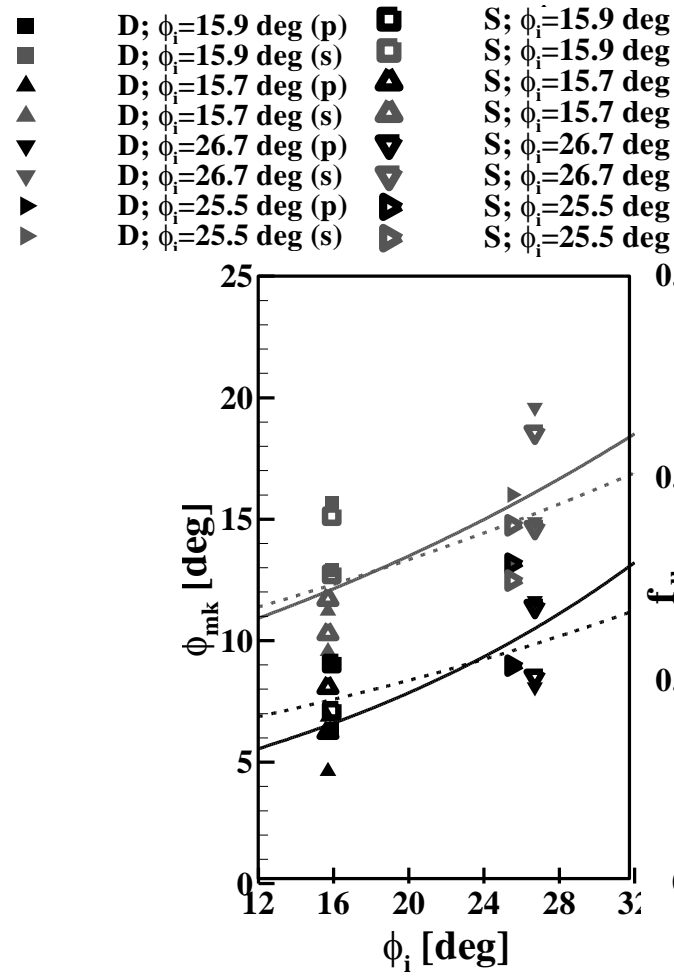
$\begin{array}{ll}\text { p) } & \text { D; curvefit (p) } \\ \text { (p) } & \text { D; curvefit (s) }\end{array}$

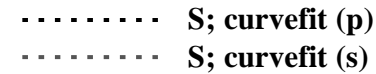
$\begin{array}{cc}\ldots . . . & S \text {; curvefit }(p) \\ \ldots . . . & S \text {; curvefit }(\mathbf{s})\end{array}$

D; $\phi_{i}=15.7 \mathrm{deg}(\mathrm{s})$

$\phi_{i}=25.5 \mathrm{deg}(\mathrm{p})$
$\phi_{\mathrm{i}}=25.5 \mathrm{deg}(\mathrm{s})$

$\mathrm{S} ; \phi=26.7 \mathrm{deg}(\mathrm{s})$
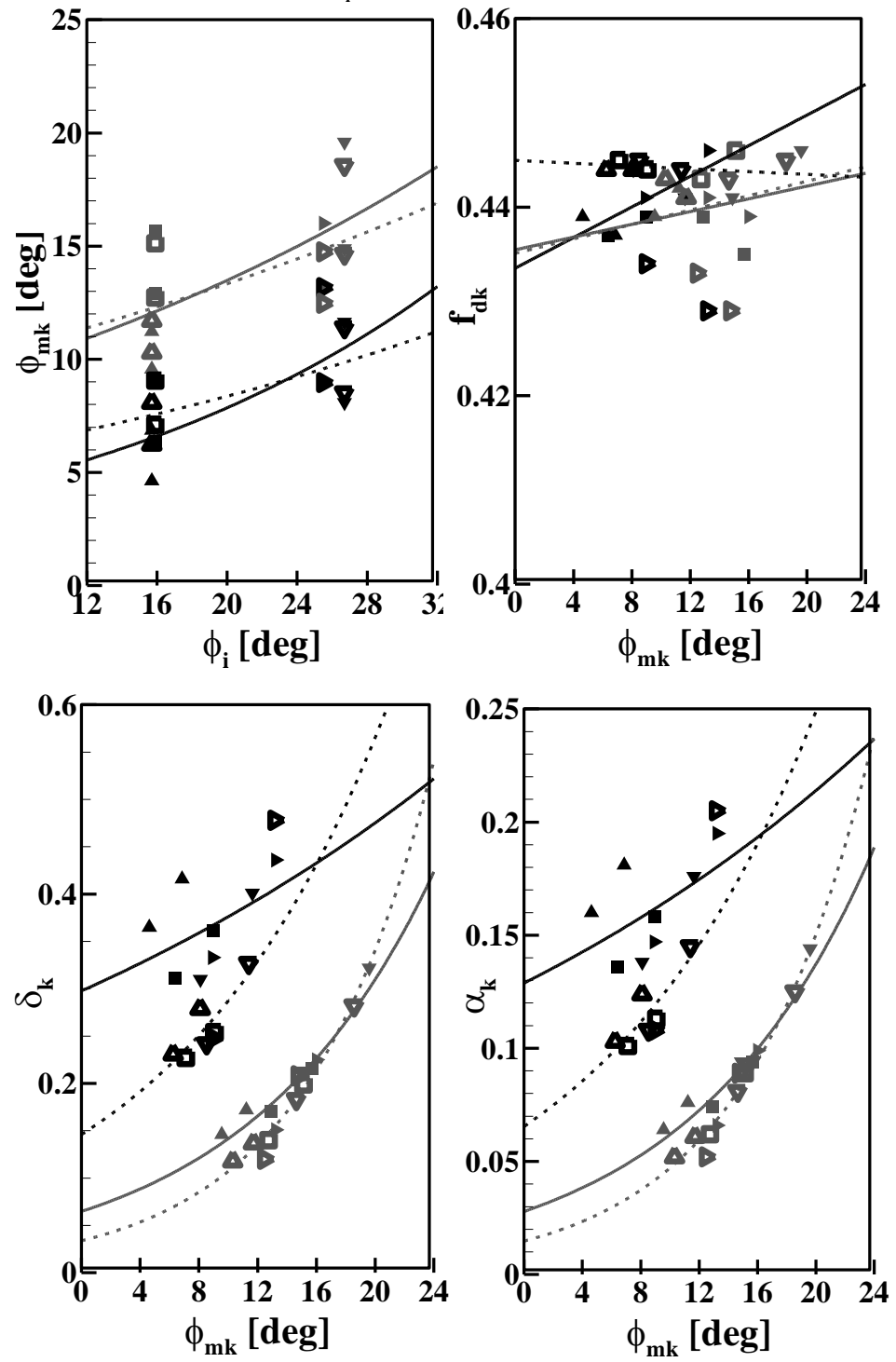

Figure 7 Experimental data and simulation prediction for variation of $\phi_{\mathrm{mk}}$ with respect to $\phi_{\mathrm{i}}$ and $\mathrm{f}_{\mathrm{dk}}, \delta_{\mathrm{k}}, \alpha_{\mathrm{k}}$ with respect to $\phi_{\mathrm{mk}}$ for damaged roll decay, calculated from roll peaks on portside (p) and starboard (s) 

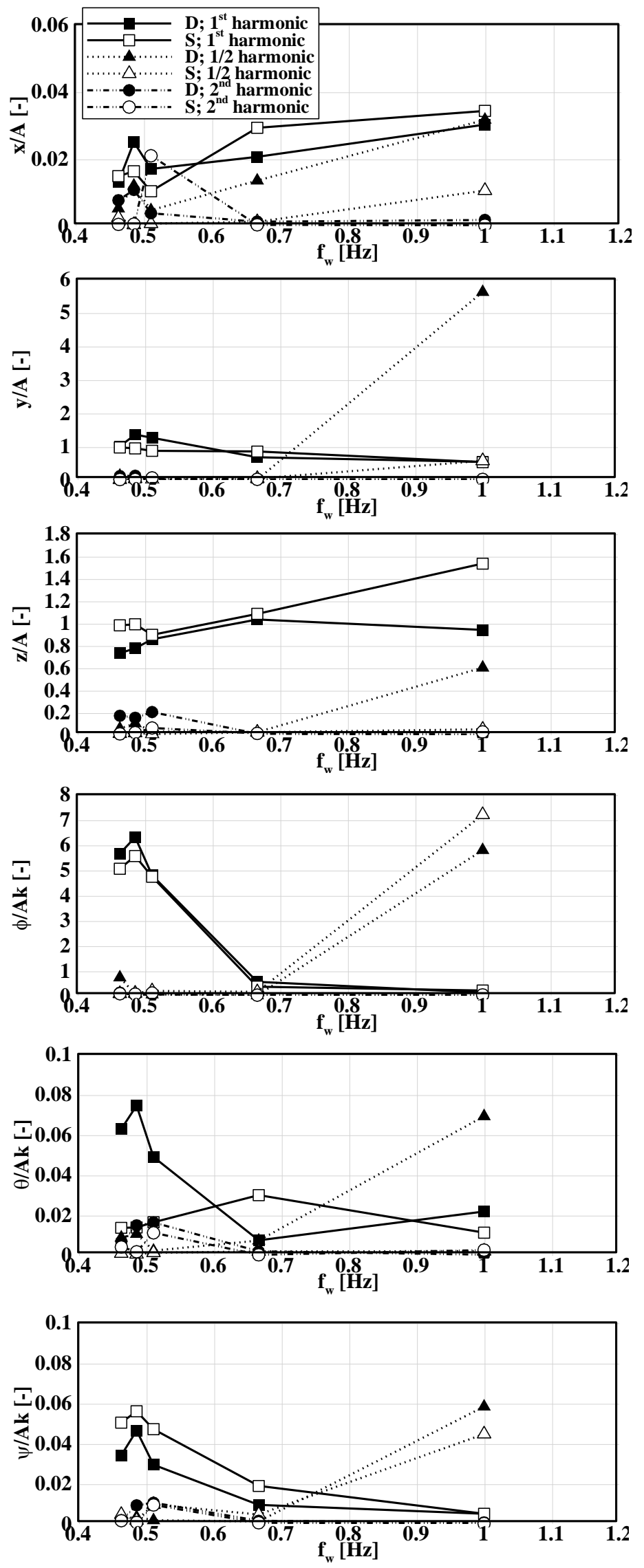

Figure 8 Experimental data and simulation prediction for harmonics of intact ship motions in beam waves with $H / \lambda=1 / 60$ for different wave frequency 

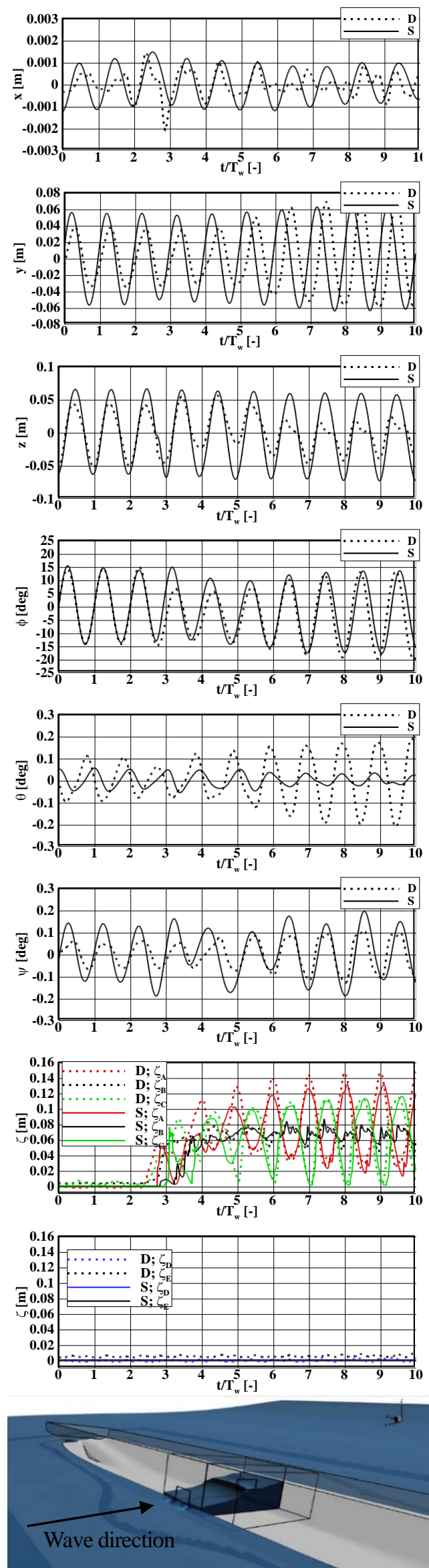

Figure 9 Experimental data and simulation prediction for time history of damaged ship motions in beam waves with $\lambda=2.42 \mathrm{~L}$ and $\mathrm{H} / \lambda=1 / 60$ 

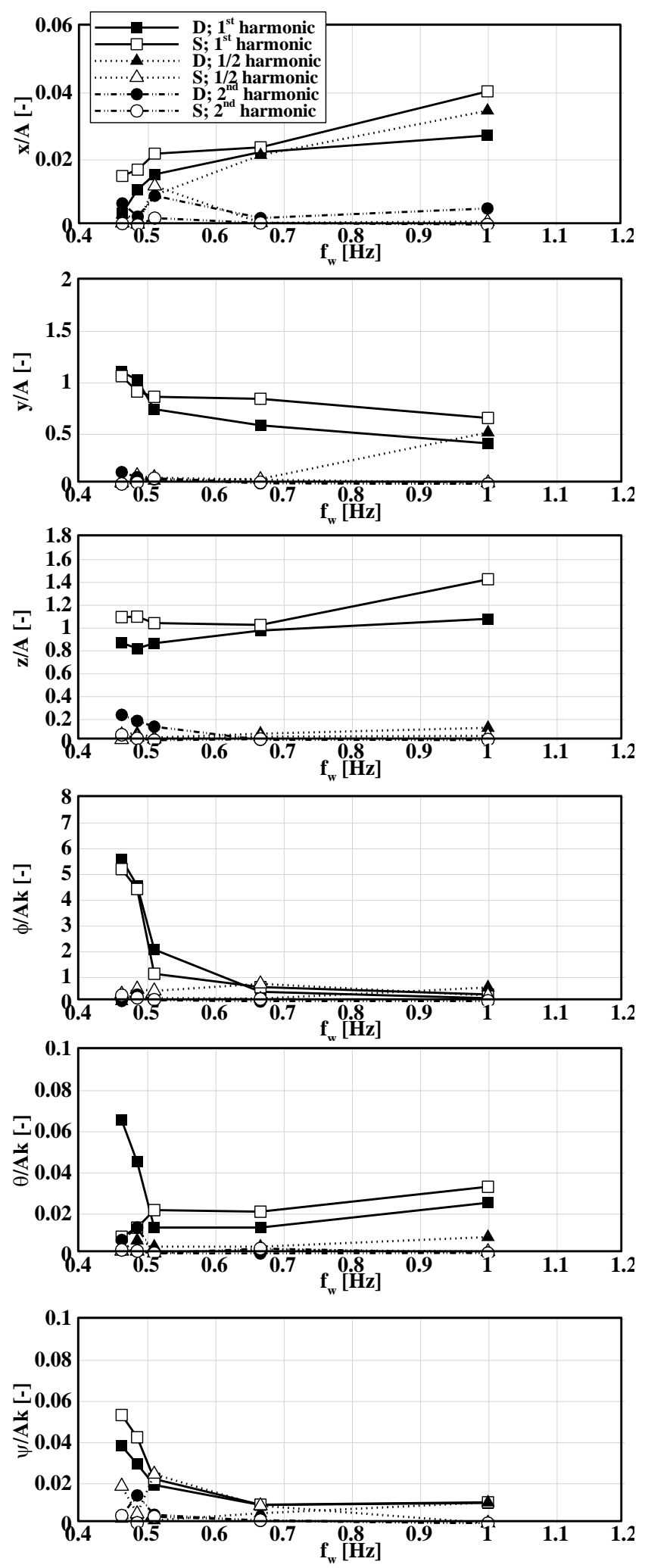

Figure 10 Experimental data and simulation prediction for harmonics of damaged ship motions in beam waves with $\mathrm{H} / \lambda=1 / 60$ for different wave frequency 